\title{
Mecanismos de alinhamento de preferências em governos multipartidários: controle de políticas públicas no presidencialismo brasileiro
}

Victor Araújo

\section{Introdução $^{1}$}

Em democracias, a execução de programas de governo é possível apenas porque o chefe do Executivo delega para seus parceiros de gabinete autoridade para tomar decisões. Em contextos em que apenas um partido ocupa o Executivo, a missão do chefe da cadeia de delegação é alinhar as preferências dos seus companheiros de partido à agenda de políticas do governo. No caso dos governos multipartidários, a heterogeneidade de preferências é a razão pela qual o déficit de informação em relação às decisões tomadas pelos partidos do gabinete é a regra, e não uma contingência como nos governos unipartidários (Andeweg, 2000; Laver, 2008; Strom e Müller, 2010).

Nos modelos formais ${ }^{2}$ utilizados para explicar a tomada de decisão em governos parlamentaristas, assume-se que a agenda do gabinete é composta de maneira colegial, o que significa que todos os ministros têm a oportunidade de externar suas preferências sobre as políticas do governo, antes que estas sejam levadas a cabo. Essa seria uma consequência de um sistema de governo que tem como característica a construção de alianças programáticas em torno de uma agenda de políticas (Laver e Schofield, 1998).

Em oposição ao formato decisório colegial, um "protótipo de porteira fechada" tem sido utilizado para explicar as democracias presidencialistas. Tendo como referência o modelo de tomada de decisão em gabinetes proposto por Laver e Shepsle (1994), o caso brasileiro é correntemente explicado a partir da noção de que a delegação ao ministro é absoluta $^{3}$, permitindo que o beneficiário extraia o máximo de retornos eleitorais do

\footnotetext{
${ }^{1}$ Agradeço a Acir Almeida, Marta Arretche, Luiza Meira Bastos, Cláudio Couto, Argelina Cheibub Figueiredo, Andréa Freitas, Paulo Hubert, Fernando Limongi, Joyce Luz, Patrícia Nabuco Martuscelli, Maurício Moya, Felipe Nunes, Juliana Oliveira, Paolo Ricci, Manoel Leonardo Santos, Glauco Peres da Silva, Thiago Silva e Sérgio Simoni pelas críticas feitas às primeiras versões do manuscrito. $O$ artigo também se beneficiou dos comentários feitos pelos participantes do VI Seminário Discente do Departamento de Ciência Política da Universidade de São Paulo e do GT "Presidencialismo de Coalizão Brasileiro" realizado no $40^{\circ}$ Encontro da Associação Nacional de Pós-Graduação e Pesquisa em Ciências Sociais - Anpocs. Sou grato também aos pareceristas anônimos que muito contribuíram para o aprimoramento do artigo. O pesquisador conta com o apoio da Fundação de Amparo à Pesquisa do Estado de São Paulo (Fapesp), processo n 2016/23215-0.

2 Embora isso não seja testificado pelas análises empíricas. Ver Elgie (1997) e Russell, Gover e Wollter (2016).

3 Trabalhos mais recentes (Batista, 2013; Gaylord e Rennó, 2015; Rennó e Wojcik, 2015) se opõem a essa visão, mostrando que a agenda de políticas do Executivo é um constructo coletivo, ou seja, não é resultante da ação isolada do chefe do gabinete de governo.
} 
MECANISMOS DE ALINHAMENTO DE PREFERÊNCIAS EM GOVERNOS MULTIPARTIDÁRIOS

ministério recebido. Nesse tipo de argumento, os partidos integrados à coalizão só se interessariam por cargos, de modo que a cooperação entre Executivo e Legislativo estaria condicionada ao apoio desses atores no Legislativo determinado pela distribuição de pastas ministeriais realizada pelo chefe do Executivo (Amorim Neto, 2000; Melo e Pereira, 2013; Raile, Pereira e Power, 2011). Levado ao extremo, nesse modelo não existe espaço para decisões colegiadas ${ }^{4}$, nem interesse dos partidos em supervisionar as áreas de policies dos partidos parceiros no gabinete.

Mas são os partidos da coalizão governamental indiferentes às políticas formuladas por seus parceiros de governo? Assim como nos casos parlamentaristas (Carroll e Cox, 2012; Martin, 2016; Martin e Vanberg, 2011; Moury, 2013), análises empíricas dos contextos presidencialistas multipartidários sugerem que o principal incentivo para que os partidos ocupem o gabinete de governo é a possibilidade de agregar suas preferências à agenda de políticas do Executivo (Alemán e Saiegh, 2007; Alemán e Tsebelis, 2011; Araújo, Freitas e Vieira, no prelo; Magar e Moraes, 2012; Zucco, 2013). No caso específico do Brasil, no Legislativo, os partidos alteram o conteúdo das políticas enviadas pelo Executivo (Freitas, 2016) e, nas comissões, bloqueiam as propostas de políticas de membros do gabinete que não estejam em consonância com a agenda do Executivo (Inácio e Rezende, 2015).

Esses trabalhos, entretanto, se concentram no momento da formulação, desconsiderando outras estratégias que podem ser utilizadas pelos membros do gabinete para diminuir o déficit de informação decorrente da delegação em governos com múltiplas preferências. O presente artigo é um empreendimento teórico e empírico que pretende mostrar que os conflitos sobre políticas existentes em gabinetes presidencialistas se refletem no comportamento dos atores partidários no parlamento, sob a forma de controle de políticas públicas. Argumento que, no caso brasileiro, os partidos da coalizão de governo, via Poder Legislativo, controlam as ações de implementação de políticas públicas dos parceiros do gabinete para mitigar os problemas provocados pela delegação em governos multipartidários.

Para tanto, utilizo como medida de controle de política pública o Requerimento de Informação (RIC), um importante instrumento de correção de assimetria de informação à disposição dos congressistas brasileiros. O custo para utilizar esse instrumento de controle é baixo, basta que qualquer legislador interessado leia o pedido de RIC em plenário. Depois disso, o RIC é protocolado pela Mesa Diretora da Câmara dos Deputados ou do Senado e encaminhado diretamente para o ministério responsável pela implementação da política em questão. Além disso, as regras institucionais do Congresso que impedem os partidos com um número pequeno de cadeiras no Legislativo de participar efetivamente no processo de escrutínio de leis nas comissões legislativas (Freitas, 2013) não se aplicam ao uso dos RIC. Por isso, os partidos não precisam negociar seu apoio em instâncias formais - como,

\footnotetext{
${ }^{4}$ Analisando 18 democracias presidencialistas na América Latina, Araújo, Silva e Vieira (2016) mostram que existe grande variação no grau de dominância do chefe do Executivo no gabinete de governo. Em alguns casos (Argentina, Bolívia, Peru, República Dominicana e Uruguai), o processo de tomada de decisão intragabinete é fortemente horizontalizado, de modo que as decisões são tomadas de maneira muito mais colegiada do que a literatura costuma supor.
} 
por exemplo, lideranças, comissões e blocos - para monitorar as políticas de seu interesse (Lemos, 2005).

A análise compreende o período entre 1995 e 2014, nos governos Fernando Henrique Cardoso (FHC), Luiz Inácio Lula da Silva (Lula) e Dilma Rousseff (Dilma). Os resultados indicam que os partidos da coalizão de governo intensificam o controle sobre as políticas delegadas aos parceiros do gabinete sempre que há aumento da expectativa de perda de informação. Em outros termos, os integrantes do governo não se contentam com a coordenação de áreas ministeriais específicas, também buscam informações e tentam influenciar as policies implementadas por outros partidos da coalizão de governo. Como consequência, formam-se redes de monitoramento intragabinete que evidenciam a motivação dos partidos para influenciar a agenda de políticas do Executivo.

A contribuição da presente análise é mostrar de que forma os conflitos intragabinete se traduzem em ações de controle das ações do Executivo. Em vez de focar na análise do processo de controle político das propostas de leis ${ }^{5}$, investigo de que forma os parlamentares utilizam as suas prerrogativas de controle horizontal - instrumentos do Poder Legislativo para controle das ações do Poder Executivo - para obter informações sobre a implementação de políticas nos ministérios dos parceiros do gabinete.

Além desta introdução, na próxima seção, "Gabinetes multipartidários no presidencialismo brasileiro", discuto os atributos dos gabinetes multipartidários formados no Brasil entre 1995 e 2014. Posteriormente, em "O que os partidos da coalizão de governo controlam?", fazendo uso de técnicas de análise quantitativa de texto, mostro quais temas e áreas ministeriais são objetos de controle dos partidos da coalizão governamental. $\mathrm{Na}$ quarta seção, "Quando os partidos monitoram os ministérios dos seus parceiros de governo?", utilizo análise econométrica para mostrar que o uso dos RIC varia positivamente com o aumento da heterogeneidade de preferências no gabinete de governo. Na quinta seção, "Redes de controle intragabinete no presidencialismo brasileiro", por meio da análise de redes, discuto as características - composição, densidade e centralidade - das redes intragabinete formadas a partir do controle horizontal realizado pelos partidos da coalizão de governo no Legislativo. Por fim, em "Conclusão", apresento as conclusões, limites e implicações da presente análise.

\section{Gabinetes multipartidários no presidencialismo brasileiro}

A alta fragmentação partidária induzida pelas regras do sistema eleitoral brasileiro (Ames, 2003), o crescimento do número de partidos efetivos presentes no Congresso Nacional (Kinzo, 2004) e a consequente impossibilidade de o partido do presidente eleger maiorias legislativas produzem incentivos para a formação de coalizões de governo (Figueiredo e Limongi, 1999). A Tabela 1 descreve os principais atributos, o grau de partidarismo e o grau de heterogeneidade de cada um dos 15 gabinetes multipartidários formados no Brasil entre 1995 e 2014.

\footnotetext{
${ }^{5}$ Como fazem Freitas (2016) e Inácio e Rezende (2015).
} 
MECANISMOS DE ALINHAMENTO DE PREFERÊNCIAS EM GOVERNOS MULTIPARTIDÁRIOS

Tabela 1

Atributos dos gabinetes de governo formados no Brasil (1995-2014)

\begin{tabular}{|l|c|c|c|c|c|}
\hline $\begin{array}{c}\text { Identificação } \\
\text { do gabinete }\end{array}$ & $\begin{array}{c}\text { Tempo } \\
\text { duração do } \\
\text { gabinete }\end{array}$ & $\begin{array}{c}\text { Número de } \\
\text { partidos do } \\
\text { gabinete }\end{array}$ & $\begin{array}{c}\text { Proporção de } \\
\text { partidos legislativos } \\
\text { no gabinete }\end{array}$ & $\begin{array}{c}\text { Taxa de } \\
\text { partidarismo } \\
\text { do gabinete }\end{array}$ & $\begin{array}{c}\text { Heterogeneidade } \\
\text { ideológica do } \\
\text { gabinete }\end{array}$ \\
\hline FHC I 1 & 480 & 4 & 0,56 & 0,58 & 0,73 \\
\hline FHC I 2 & 979 & 5 & 0,77 & 0,75 & 0,78 \\
\hline FHC II 1 & 1.159 & 4 & 0,68 & 0,78 & 0,50 \\
\hline FHC II 2 & 300 & 4 & 0,45 & 0,39 & 0,25 \\
\hline Lula I 1 & 386 & 8 & 0,43 & 0,83 & 0,74 \\
\hline Lula I 2 & 374 & 8 & 0,62 & 0,83 & 0,91 \\
\hline Lula I 3 & 107 & 7 & 0,58 & 0,87 & 0,60 \\
\hline Lula I 4 & 63 & 6 & 0,58 & 0,83 & 0,64 \\
\hline Lula I 5 & 526 & 7 & 0,70 & 0,78 & 0,79 \\
\hline Lula II 1 & 90 & 8 & 0,61 & 0,74 & 0,85 \\
\hline Lula II 2 & 909 & 8 & 0,68 & 0,83 & 0,85 \\
\hline Lula II 3 & 459 & 8 & 0,63 & 0,83 & 0,67 \\
\hline Dilma I1 & 425 & 7 & 0,64 & 0,88 & 0,60 \\
\hline Dilma I2 & 579 & 8 & 0,61 & 0,79 & 0,65 \\
\hline Dilma I3 & 819 & 7 & 0,56 & 0,79 & 0,77 \\
\hline
\end{tabular}

Fonte: Elaborada pelo autor a partir dos dados do Cebrap ${ }^{6}$.

A taxa de partidarismo considera a proporção de ministros com apoio partidário no Legislativo. Gabinetes com baixas taxas de partidarismo são, na maior parte dos casos7, menos heterogêneos, em virtude do número reduzido de atores partidários que ocupam o governo. Nesse sentido, os dois indicadores são complementares, uma vez que o cálculo da heterogeneidade permite dimensionar o grau de dispersão dessas preferências partidárias.

O grau de heterogeneidade do gabinete ${ }^{8}$ foi calculado a partir dos scores utilizados por Power e Zucco (2009), tendo como referência o posicionamento ideológico dos partidos representados no Congresso Nacional $^{9}$. O nível de dispersão das preferências do gabinete é o resultado da soma das diferenças entre o posicionamento ideológico do partido formador e o posicionamento ideológico dos outros partidos que compõem um dado gabinete ${ }^{10}$, ponderado pelo número de partidos que integram o governo. 0 indicador varia entre 0 e 1 , em que 1 indica o nível máximo de heterogeneidade e 0 significa o menor nível possível de heterogeneidade observado em um gabinete de governo.

Nenhum dos três presidentes analisados - FHC, Lula e Dilma - foi capaz de construir uma rede de apoio político com partidos próximos no espectro ideológico. Todavia, a dispersão de preferências observada nos governos petistas é consideravelmente maior. Os gabinetes formados durante os dois mandatos do presidente FHC, do PSDB, foram compostos por um número médio de quatro partidos. As características distintivas

\footnotetext{
${ }^{6}$ Dados do Cebrap nas Tabelas 1 e 5 disponíveis em: <http://neci.fflch.usp.br/node/506>. Acesso em: 31 jul. 2017.

7 Apesar de a ocorrência ser improvável na prática, coalizões pequenas podem apresentar alto grau de heterogeneidade. Um partido formador de centro pode compor uma coalizão com um partido de extrema esquerda e outro partido de extrema direita, por exemplo.

${ }^{8}$ A operacionalização do cálculo pode ser visualizada no Anexo.

${ }^{9}$ Dados disponíveis em: <https://dataverse.harvard.edu/dataverse/bls>. Acesso em: 31 jul. 2017.

10 Em termos técnicos, trata-se da soma das diferenças das distâncias euclidianas.
} 
desse período são a proximidade relativa das preferências dos partidos que integram o governo e a baixa média da taxa de partidarismo - 0,62. Os gabinetes do governo FHC apresentam um padrão menos heterogêneo - média de 0,57 - quando comparados aos gabinetes formados nos mandatos do presidente Lula e da presidente Dilma, ambos do PT. $\mathrm{O}$ padrão é explicado pelo elevado número de ministros técnicos ${ }^{11}$ nomeados naquele período.

A média de heterogeneidade dos gabinetes de 0,76 e 0,67, respectivamente, é resultante da formação de governos grandes - média de 7,3 partidos nos mandatos dos presidentes Lula e Dilma - e com preferências dispersas. Esses elevados scores de heterogeneidade são decorrentes das altas taxas de partidarismo registradas nos governos dos dois presidentes do PT.

A maior dispersão das preferências dos partidos no governo implica custos de coordenação desses atores e torna mais difícil o estabelecimento de processos de cooperação (Epstein e O'Halloran, 1999). Mais do que isso, agrava o problema da assimetria de informação inerente à delegação, criando fortes incentivos para o estabelecimento de redes de monitoramento entre os integrantes do gabinete de governo (Müller e Strom, 2003; Thies, 2001).

O controle de implementação de políticas permite que todos os partidos do gabinete tenham a chance de influenciar as ações executadas por outros partidos que integram o Executivo, mesmo passado o processo de elaboração e discussão das políticas. Na mesma linha dos trabalhos de O’Donnell (1998) e Lemos e Power (2013), utilizo o termo "controle horizontal" para me referir às prerrogativas constitucionalmente delegadas ao Poder Legislativo para monitorar - solicitando informações e cobrando providências acerca da implementação de políticas públicas - as ações do Poder Executivo.

O Requerimento de Informação (RIC) é um dispositivo de controle horizontal à disposição dos parlamentares brasileiros. Qualquer deputado ${ }^{12}$ em exercício pode protocolar, junto à Mesa Diretora da Câmara dos Deputados, pedido de investigação das ações de algum ministério e/ou órgão do Executivo. A despeito de seu baixo custo de apresentação ${ }^{13}$, por meio do Requerimento de Informação os parlamentares são capazes de exercer efetivo controle sobre as ações da burocracia ministerial (Lemos, 2005). Qualquer ato, ação ou programa relacionado à implementação de políticas públicas pode ser alvo de controle dos parlamentares. Os órgãos notificados devem apresentar as devidas explicações sob pena de crime de responsabilidade ${ }^{14}$. O controle horizontal é, portanto, a

\footnotetext{
11 Ministros técnicos (sem filiação partidária) foram considerados como sendo da cota do presidente. Isto é, assumo que esses ministros possuem as mesmas preferências do partido formador do gabinete.

12 Os senadores também podem apresentar Requerimentos de Informação, mas não serão analisados neste artigo.

13 O Requerimento de Informação deve ser elaborado por escrito e apresentado no plenário de qualquer uma das Casas (Câmara dos Deputados ou Senado), onde será lido, submetido à votação e aprovado por maioria simples.

14 Como prescrevem o artigo 116 do regimento interno e a Questão de Ordem 469/2004 da Câmara dos Deputados, a recusa ou o não atendimento no prazo de 30 dias dos pedidos escritos de informação a ministro de Estado, bem como a prestação de informações falsas, serão considerados crime de responsabilidade, desde que o parlamentar requerente processe o ministro de Estado responsável perante o Supremo Tribunal Federal.
} 
MECANISMOS DE ALINHAMENTO DE PREFERÊNCIAS EM GOVERNOS MULTIPARTIDÁRIOS

forma menos custosa e eficiente de conhecer as políticas dos parceiros da coalizão e de monitorar as ações de diferentes ministérios de acordo com as prioridades do partido.

\section{Gráfico 1 \\ Variação do número de Requerimentos de Informação em função do grau de heterogeneidade ideológica do gabinete de governo (1995-2014)}

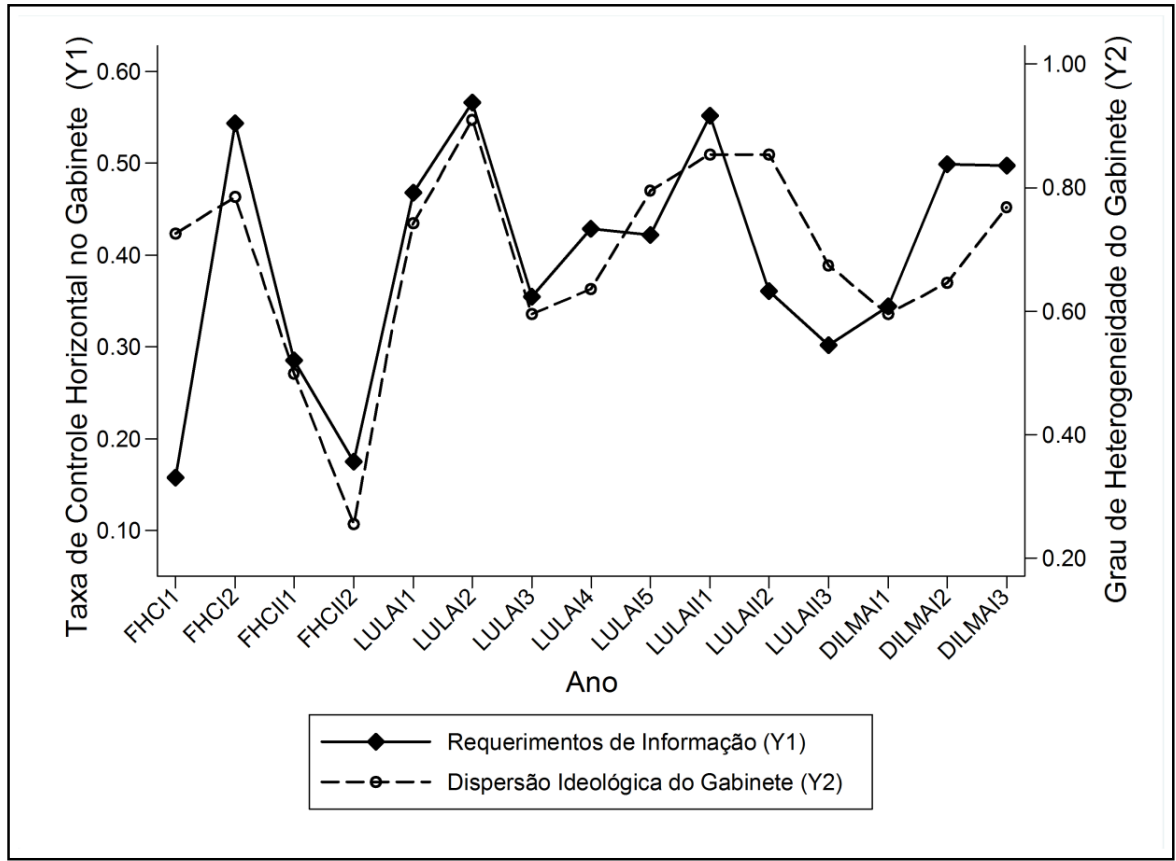

Fonte: Elaborado pelo autor a partir dos dados da Câmara dos Deputados ${ }^{15}$.

No Gráfico 1 pode ser visualizada a tendência do uso de Requerimentos de Informação pelos partidos da coalizão de governo para controlar as ações de implementação de políticas dos seus parceiros de gabinete. Foram consideradas todas as 22.688 ações de controle apresentadas pelos parlamentares da Câmara dos Deputados entre os anos de 1995 e $2014^{16}$. A linha sólida representa a variação da proporção de Requerimentos de Informação apresentados pelos partidos da coalizão, denominada "taxa de controle horizontal no gabinete" e representada no eixo (Y1). A linha tracejada diz respeito ao grau de heterogeneidade de preferências em cada gabinete ${ }^{17}$ formado no Brasil no mesmo período (Y2).

A análise no tempo dos eixos (Y1) e (Y2) evidencia a forte correlação entre a taxa de controle horizontal e o grau de heterogeneidade dos gabinetes. Medido pelo coeficiente

15 Dados da Câmara do Deputados nas tabelas, gráficos e figuras deste artigo disponíveis em:

<http://www2.camara.leg.br/transparencia/dados-abertos/dados-abertos-legislativo/webservices>. Acesso em: 31 jul. 2017.

16 Nesse período, os partidos representados no Legislativo protocolaram 25.743 ações de controle de implementação de políticas públicas. Desse total, foram excluídas aquelas em que o conteúdo não explicita claramente a política, o programa ou a área de policy controlada pelo parlamentar, restando, assim, 22.688 Requerimentos de Informação.

17 Assim como na Tabela 1, a heterogeneidade ideológica dos gabinetes foi calculada a partir dos dados presentes em Power e Zucco (2009). 
de Pearson, as duas linhas apresentam correlação de $0.71^{18}$ em uma escala que varia entre 0 e 1 . Isso indica que os partidos da coalizão intensificam o controle sobre as políticas implementadas por seus parceiros de governo quando o gabinete é composto por preferências mais dispersas e/ou extremas.

Entre 1996 e 2002, verifica-se uma tendência de queda na taxa de controle horizontal no gabinete, fato que está relacionado com a formação de governos menos heterogêneos - com partidos que possuem posições ideológicas mais próximas às preferências do partido formador. A tendência verificada entre 2003 e 2014 é contrária. Nesse período houve aumento médio da taxa de controle horizontal no gabinete. Essa tendência está associada com a formação de gabinetes maiores e mais heterogêneos com a presença de vários atores partidários com posições ideológicas distantes da preferência do partido formador. Os dados indicam que, para além da natureza accountable das ações de controle empreendidas pelos partidos da coalizão, o uso dessa prerrogativa de controle guarda relação com a expectativa de perda de informação dos partidos que ocupam o gabinete. Três pontos de inflexão representados no Gráfico 1 são sintomáticos a esse respeito.

No primeiro ponto, no gabinete FHC I2 (1996), foi registrado o primeiro pico de controle intragabinete. Nesse período, a taxa de controle horizontal mais que triplicou, variando de $16,2 \%$ no gabinete FHC I1 para $54,1 \%$ no gabinete FHC I2. Esse efeito é decorrente da entrada do PPB no governo, um partido com posição ideológica distante da preferência do partido formador e que desempenhou um papel ativo nas ações de monitoramento.

No segundo ponto, no gabinete FHC II2 (2002), a taxa de controle horizontal cai bruscamente ${ }^{19}$ em função do governo menos heterogêneo formado nesse período. Por opção do presidente à época, FHC (PSDB), inúmeras pastas ministeriais foram distribuídas para ministros técnicos de sua cota pessoal. A nomeação desses técnicos foi viabilizada pela saída de um dos principais partidos parceiros no governo, o $\mathrm{PFL}$, e pelo grande apoio legislativo de que gozava o presidente nesse período. O governo passou a ser composto, principalmente, por ministros do partido do presidente ou por ministros técnicos por ele indicados. Assim, em decorrência da baixa taxa de partidarismo do gabinete, os incentivos para o controle horizontal foram reduzidos.

O terceiro ponto de inflexão ocorreu no gabinete Lula I1, o primeiro formado pelo presidente em 2003. Diferente do período FHC, o plano de conseguir implementar uma extensa agenda de políticas sociais foi viabilizado por uma densa rede de apoio político, razão pela qual o governo foi ocupado por partidos de diferentes matizes ideológicas e distintas preferências sobre políticas (Melo e Nunes, 2009). Esse gabinete registrou a maior taxa de partidarismo desde o início da série em 1995. O controle ex post sobre a implementação das políticas públicas foi uma estratégia recorrente entre os partidos integrantes do gabinete. No primeiro mandato da presidente Dilma, também um governo marcado pela composição de gabinetes grandes e heterogêneos, é possível observar a

\footnotetext{
18 Ao nível de $99 \%$ de confiança.

${ }^{19}$ A taxa de controle horizontal no gabinete registrada nesse ponto do tempo foi de $0,18 \%$.
} 
MECANISMOS DE ALINHAMENTO DE PREFERÊNCIAS EM GOVERNOS MULTIPARTIDÁRIOS

mesma tendência de alta média de controle horizontal intragabinete em função da assimetria de informação decorrente da composição de governos multipartidários.

\section{O que os partidos da coalizão de governo controlam?}

$\mathrm{Na}$ seção anterior foi demonstrado que, na trajetória recente da democracia brasileira, a formação de gabinetes grandes e com preferências dispersas produz incentivos para a ocorrência de controle mútuo intragabinete entre os partidos. Nesta seção o objetivo é analisar o conteúdo das ações de controle executadas pelos partidos. Embora exista a presunção de que as prerrogativas de controle do Legislativo sejam utilizadas exclusivamente para o controle de aspectos relacionados à corrupção (O'Donnell, 1998), os partidos também fazem uso de suas prerrogativas para monitorar um amplo espectro de políticas.

Para tanto, utilizo técnicas de análise quantitativa de texto (machine learning) que permitem analisar a frequência com que termos aparecem em documentos de um dado corpus, uma matriz de dados composta por arquivos de texto. Mais especificamente, faço uso do método Gibbs Sampling (Chang, 2012), algoritmo não supervisionado ${ }^{20}$ derivado do amplamente utilizado Latent Dirichlet Allocation (LDA) (Blei, Ng e Jordan, 2003), um modelo bayesiano para dados discretos que permite extrair probabilisticamente tópicos de uma matriz de dados composta por palavras.

O corpus foi composto por todos os Requerimentos de Informação apresentados pelos deputados federais de partidos da coalizão entre 1995 e 2014 ( $N=9.705)$. A unidade de análise da matriz de dados é o Requerimento de Informação (RIC) que conta com uma coluna texto, uma variável que descreve o conteúdo da ação de controle apresentada por cada parlamentar. Dado o objetivo de controlar as ações de implementação do Executivo, cada RIC detalha o programa e a área ministerial de que o parlamentar deseja obter informações.

Abaixo menciono quatro exemplos de RIC apresentados por parlamentares na Câmara dos Deputados com o objetivo de monitorar políticas relacionadas às áreas de infraestrutura, transportes, meio ambiente e educação:

RIC 1 [Infraestrutura]: "Solicita informações ao Senhor Ministro da Defesa sobre projetos de obras do PAC - Programa de Aceleração do Crescimento em aeroportos";

RIC 2 [Transportes]: "Solicita informações ao Senhor Ministro dos Transportes sobre o Plano Nacional de Logística e Transportes (PNLT)";

RIC 3 [Meio Ambiente]: "Solicita informações ao Senhor Ministro da Agricultura, Pecuária e Abastecimento sobre plantio de soja transgênica";

\footnotetext{
${ }^{20}$ Algoritmos não supervisionados são utilizados com a finalidade de encontrar padrões em extensas bases de dados, permitindo que itens, temas, tópicos ou clusters sejam corretamente classificados (James et al., 2013; Athey e Imbens, 2017).
} 
RIC 4 [Educação]: "Solicita informações ao Senhor Ministro da Educação acerca da Execução do Programa Nacional de Reestruturação e Aquisição de Equipamentos para a rede escolar pública de educação infantil (Proinfância)".

Do ponto de vista computacional, foi utilizado o software $\mathrm{R}^{21}$ para estimar um modelo LDA. Seguindo o procedimento indicado por Hornik e Grün (2011), o método Gibbs Sampling foi programado para extrair o valor máximo de 15 tópicos, com 2 mil iterações 22 . Apenas o melhor modelo log-likehood ajustado pelo Gibbs Sampling é retornado. Embora a escolha do número de tópicos seja arbitrária, esse número variou entre 2 e $100^{23}$. 0 modelo funciona bem se utilizamos apenas dois tópicos, embora, nesse caso, o algoritmo não seja capaz de realizar uma análise refinada dos termos que compõem a matriz de dados. Dessa forma, como sugerem Chang et al. (2009), o número de tópicos utilizados foi definido de acordo com a consistência e a validação dos termos extraídos da matriz de palavras. Foram considerados todos os tópicos reportados (no limite de 15) pelo software $\mathrm{R}$ com termos não repetidos e que nos permitiram, do ponto de vista qualitativo, definir padrões e relacioná-los a temas.

O resultado mais básico da análise quantitativa de texto realizada pode ser visto na Tabela 2, em que foram dispostos os temas objeto de controle dos parlamentares por governo (FHC, Lula e Dilma), de acordo com a frequência com que eles aparecem no corpus. Como pode ser visto, os partidos da coalizão monitoram um amplo espectro de políticas, sobretudo aquelas mais salientes. Embora exista variação na ordem em que os temas aparecem em cada governo, há três termos comuns aos governos analisados: "Fazenda", "Saúde" e "Social". Outro aspecto importante é a variação entre os governos: enquanto "Orçamento" foi o termo mais frequente durante o governo FHC, outras áreas como "Ciência", "Tecnologia", "Cultura" e "Justiça" foram objeto de controle apenas durante os governos Lula e Dilma.

\footnotetext{
${ }^{21}$ Para estimar o método Collapsed Gibbs Sampling, foi utilizado o pacote topicmodels, disponível em: <https://cran.r-project.org/web/packages/topicmodels/index.html>.

22 Retornando 100 iterações para cada 1.000 iterações.

${ }^{23}$ Foram realizados testes de validação. Os resultados indicam que o número de tópicos escolhidos não tem impacto sobre o ajuste do modelo sobre o conjunto de dados.
} 
MECANISMOS DE ALINHAMENTO DE PREFERÊNCIAS EM GOVERNOS MULTIPARTIDÁRIOS

Tabela 2

Lista dos dez temas mais controlados pelos partidos da coalizão de governo

\begin{tabular}{|c|c|c|c|c|c|c|}
\hline & \multicolumn{2}{|c|}{ FHC } & \multicolumn{2}{c|}{ Lula } & \multicolumn{2}{c|}{ Dilma } \\
\hline Ranking & Termo & Frequência & Termo & Frequência & Termo & Frequência \\
\hline 1 & Orçamento & 913 & Saúde & 688 & Saúde & 166 \\
\hline 2 & Fazenda & 477 & Amazônia & 547 & Educação & 153 \\
\hline 3 & Saúde & 293 & Energia & 464 & Desenvolvimento & 133 \\
\hline 4 & Social & 267 & Desenvolvimento & 350 & Transportes & 91 \\
\hline 5 & Energia & 224 & Fazenda & 344 & Fazenda & 90 \\
\hline 6 & Planejamento & 214 & Social & 286 & Energia & 77 \\
\hline 7 & Desenvolvimento & 209 & Justiça & 274 & Tecnologia & 74 \\
\hline 8 & Transportes & 191 & Educação & 272 & Ciência & 71 \\
\hline 9 & Ambiente & 180 & Comunicação & 227 & Cultura & 68 \\
\hline 10 & Educação & 169 & Defesa & 221 & Social & 67 \\
\hline
\end{tabular}

Fonte: Elaborada pelo autor a partir das informações da Câmara dos Deputados.

Uma grande vantagem da análise quantitativa de texto é que ela nos permite utilizar a combinação de termos para classificar tópicos. Posto em termos simples, por meio de estimações de máxima verossimilhança, o algoritmo é capaz de calcular a probabilidade de termos frequentes no corpus, conjuntamente, formarem uma dimensão de análise relevante. No presente artigo, essa funcionalidade foi utilizada para identificar as áreas ministeriais monitoradas pelos partidos do gabinete. A Tabela 7 (no Anexo) informa as dez áreas ministeriais que mais foram objeto de controle dos partidos da coalizão de governo, considerando os governos FHC, Lula e Dilma.

A coluna "Termos" contém os termos que probabilisticamente variam conjuntamente na matriz de dados. A coluna "Ministérios" informa a área ministerial à qual se referem os termos. Vale ressaltar, em primeiro lugar, que existe um padrão de controle por parte dos partidos da coalizão de governo. Com exceção dos ministérios da Previdência Social e do Desenvolvimento Social que aparecem, respectivamente, apenas nos governos FHC e Dilma, todas as outras áreas ministeriais foram objeto de intenso controle nos três governos analisados.

Em segundo lugar, alguns ministérios como "Fazenda", "Planejamento" e "Transportes", independentemente do governo, são sempre alvo de intenso controle mútuo entre os partidos do gabinete. Enquanto o Ministério da Fazenda decide sobre os rumos da economia e, portanto, a capacidade de gasto dos partidos em curto, médio e longo prazo, a área do Planejamento é responsável por decidir como, quando e quem terá recursos para implementar políticas. No caso do Ministério dos Transportes, trata-se de uma área com muitos recursos e enorme capilaridade, de modo que um grande número de ações de implementação é de responsabilidade dessa área.

Por fim, cumpre destacar que a saliência das áreas ministeriais varia em cada governo - ver, por exemplo, a classificação dos ministérios do Meio Ambiente e das Minas e Energia em cada um dos mandatos presidenciais. Isso sugere que medidas de saliência ministerial deveriam considerar esse componente dinâmico do comportamento dos atores partidários, ou seja, as preferências sobre policy dos partidos não são estáticas - como 
sugere, por exemplo, a análise realizada por Batista (2017) -, mas variáveis no tempo a depender de fatores institucionais e conjunturais.

\section{Quando os partidos monitoram os ministérios dos seus parceiros de governo?}

Nesta seção, será testada, de forma sistemática, a hipótese de que os partidos da coalizão intensificam o controle quando a expectativa de assimetria de informação aumenta, ou seja, analiso em quais circunstâncias os integrantes do gabinete buscam informações e tentam influenciar as políticas implementadas por outros partidos do governo. Formalmente, testo a seguinte hipótese:

$\mathrm{H} 1$ : quanto maior a taxa de heterogeneidade ideológica do gabinete, maior a probabilidade de um parlamentar que integra um partido da coalizão de governo apresentar um RIC.

Do ponto de vista operacional, a probabilidade de que ações de controle de políticas públicas sejam executadas por um partido da coalizão aumenta nos contextos em que o gabinete de governo é composto por preferências ideológicas dispersas - circunstâncias nas quais há aumento do déficit de informação para os partidos governistas?

A unidade de análise é o controle realizado pelos parlamentares da Câmara dos Deputados entre 1995 e 2014. Para garantir que a significância das variáveis não fosse função apenas do elevado número de casos, foi construído uma subsample a partir de uma seleção aleatória estratificada do universo de Requerimentos de Informação. Foram observados os seguintes critérios para a construção da amostra: i) número de partidos que integram o gabinete; ii) duração do gabinete; e iii) peso de cada partido no gabinete em função do tempo de duração do gabinete. No total, foram amostradas 817 ações de controle do universo de 22.688 Requerimentos de Informação apresentados na Câmara dos Deputados entre 1995 e 2014.

A variável dependente assume o valor 1 quando o parlamentar que apresenta o RIC - a proposta de controle horizontal - pertence ao partido da coalizão. Se o parlamentar pertence a qualquer outro partido, assume o valor 0 . O principal regressor do modelo é o indicador de heterogeneidade ideológica (heterogeneidade) do gabinete. Esse é o mesmo indicador utilizado por Power e Zucco (2009) e apresentado na Tabela 1. Espero que a probabilidade de um parlamentar da coalizão de governo realizar controle horizontal aumente em função da variação positiva desse indicador.

Assumo que a relação entre esses dois indicadores é uma função de fatores endógenos e exógenos à atividade parlamentar. Embora o argumento de que os problemas do gabinete se refletem no parlamento seja baseado na ideia de que o comportamento dos parlamentares pode ser predito apenas por variáveis relacionadas à relação ExecutivoLegislativo (fatores endógenos), parto da hipótese de que fatores externos à Câmara dos Deputados (fatores exógenos) podem também influenciar o transcurso do processo legislativo. 
MECANISMOS DE ALINHAMENTO DE PREFERÊNCIAS EM GOVERNOS MULTIPARTIDÁRIOS

Dentre os fatores endógenos, considero o tamanho da coalizão de governo (tamanho coalizão) e a taxa de apoio - disciplina legislativa - dos partidos da coalizão às propostas de políticas do Executivo ${ }^{24}$ (disciplina coalizão). No primeiro caso, espero que coalizões de governo maiores, que congregam mais partidos, afetem positivamente a probabilidade de um parlamentar da coalizão controlar as ações de implementação de um partido parceiro do gabinete. A inclusão de um indicador que prediz o relacionamento entre Executivo e Legislativo tem por objetivo controlar o teste de hipótese por uma medida que explana um argumento rival. Sendo assim, espero que não haja correlação estatisticamente significante dessa variável com a probabilidade de os partidos realizarem ações de controle horizontal ${ }^{25}$.

\section{Tabela 3}

Descritivas das variáveis utilizadas no modelo logístico binomial

\begin{tabular}{|l|c|c|c|c|c|}
\hline \multicolumn{1}{|c|}{ Variáveis } & N & Média & Desvio-padrão & Mín. & Máx. \\
\hline Dependente & 817 & 0.3782 & 0.4852 & 0 & 1 \\
\hline Ciclo eleitoral & 817 & 695.77 & 436.41 & 18.39 & 1454.12 \\
\hline Disciplina coalizão & 817 & 0.8342 & 0.0751 & 0.6919 & 0.9207 \\
\hline Governo & 817 & 0.1738 & 0.3791 & 0 & 1 \\
\hline Heterogeneidade & 817 & 0.7232 & 0.1150 & 0.25 & 0.91 \\
\hline Honeymoon & 817 & 0.3170 & 0.4655 & 0 & 1 \\
\hline Inflação & 817 & 0.4824 & 0.2398 & 0.24 & 1.59 \\
\hline Popularidade & 817 & 47.86 & 14.86 & 20.38 & 77.7 \\
\hline Tamanho coalizão & 817 & 318.5 & 42.33 & 219 & 396 \\
\hline
\end{tabular}

Fonte: Elaborada pelo autor.

Em relação aos fatores exógenos, considero a popularidade do chefe do Executivo (popularidade), medida pela proporção de indivíduos que avaliam o governo "ótimo" ou "bom" na data de apresentação do RIC ${ }^{26}$, e a taxa de inflação ${ }^{27}$ (inflação), também na data de apresentação do RIC. Dado o objetivo dos partidos de conseguir informações sobre as políticas que lhes interessam, espero que as duas variáveis tenham efeito nulo sobre a decisão dos parlamentares de controlar as ações de implementação dos parceiros de governo.

Além disso, é preciso considerar os efeitos relacionados ao timing da apresentação das propostas de controle. Para tanto, considero a distância em dias entre a data de

\footnotetext{
${ }^{24}$ A taxa de apoio no indicador disciplina coalizão foi mensurada através do índice de Rice, da forma como foi operacionalizado por Figueiredo e Limongi (1999) para investigar a disciplina partidária no Congresso brasileiro. Operacionalmente, trata-se de, a partir das votações nominais, avaliar a adesão dos partidos da coalizão aos projetos de iniciativa do Executivo. Os dados estão disponíveis em: <http://neci.fflch.usp.br/node/506>. Acesso em: 31 jul. 2017.

25 Mesmo que os partidos da coalizão se comportem de maneira disciplinada em todas as votações no Legislativo, dado o objetivo de monitorar os parceiros do gabinete responsáveis pelas políticas de seu interesse, os partidos empreenderão ações de controle horizontal.

26 As pesquisas de popularidade do presidente da República foram realizadas pelo Datafolha e disponibilizadas pelo Centro de Estudos da Metrópole (CEM/Cepid) no seguinte endereço: <http://centrodametropole.org.br/avaliacao/presidentes/home>. Acesso em: 31 jul. 2017.

27 A taxa de inflação considera o Índice Nacional de Preço ao Consumidor Amplo (IPCA). Foram utilizados os valores da pesquisa realizada mensalmente pelo Instituto Brasileiro de Geografia e Estatística (IBGE) e disponibilizados pelo Centro de Estudos da Metrópole (CEM/Cepid) no seguinte endereço: <http://centrodametropole.org.br/avaliacao/presidentes/home>.
} 
apresentação do RIC e a data da próxima eleição presidencial (ciclo eleitoral), e se a proposta de controle foi apresentada no primeiro ano do mandato presidencial (honeymoon), sob a hipótese de que existe uma fase de "lua de mel" em que os atores do Legislativo adotam uma postura mais branda em relação ao controle das ações realizadas pelo Executivo. Mais uma vez, em virtude da disposição contínua dos partidos para mitigar a perda de informação inerente à delegação em governos multipartidários, espero efeito nulo desses dois indicadores sobre a variável dependente. Por fim, utilizo como controle uma variável que considera as heterogeneidades de governo (governo). Trata-se de uma variável dicotômica que indica se, na data de apresentação da proposta de controle, o partido formador do gabinete era o PSDB (1) ou o PT (0), os respectivos partidos dos três presidentes que governaram o Brasil entre 1995 e 2014.

O Gráfico 2 apresenta os resultados do modelo logístico binomial ajustado ${ }^{28}$. $\mathrm{Na}$ primeira especificação (modelo 1 ), o indicador de heterogeneidade ideológica do gabinete foi regredido considerando os fatores endógenos, ou seja, tamanho coalizão, disciplina coalizão, e os controles relacionados ao tempo - ciclo eleitoral e honeymoon. Nesse cenário, observamos um efeito positivo e significante da variável heterogeneidade sobre a variável dependente. A cada acréscimo de um ponto percentual desse indicador, a probabilidade de um partido da coalizão realizar controle sobre seus parceiros de governo aumenta 460\% (IC95\%: $[0,44 ; 3,03])^{29}$. Da mesma forma, existe um efeito positivo e significante da medida tamanho coalizão, uma variável que pode ser lida como um indicador alternativo de heterogeneidade no gabinete de governo. Vale ressaltar que nenhum dos outros indicadores utilizados como controle apresentou significância estatística. De acordo com o esperado, a variação da disciplina da coalizão de governo e a temporalidade não reduzem os incentivos para que um partido da coalizão realize controle sobre as ações de implementação de um partido parceiro de governo.

$\mathrm{Na}$ segunda especificação (modelo 2 ), foram acrescidas as variáveis relacionadas aos fatores exógenos. Nesse cenário, enquanto o efeito da variável tamanho coalizão torna-se nulo, o indicador de heterogeneidade ideológica do gabinete permaneceu positivo e significante em termos estatísticos e substantivos, mesmo quando a hipótese foi testada em condições mais exigentes. Em média, a cada acréscimo de um ponto percentual na variável heterogeneidade, observamos um aumento de $440 \%$ (IC95\%: $[0,22 ; 3,15])$ na probabilidade de um parlamentar de um partido da coalizão apresentar uma ação de controle horizontal.

\footnotetext{
28 Na Tabela 6 (no Anexo) foram reportados o coeficiente, a razão de chances e o erro-padrão de cada uma das variáveis apresentadas no Gráfico 2.

29 Para chegar a esse valor foi utilizada a seguinte fórmula: (Razão de Chance -1 ) *100.
} 
MECANISMOS DE ALINHAMENTO DE PREFERÊNCIAS EM GOVERNOS MULTIPARTIDÁRIOS

Gráfico 2

Impacto da heterogeneidade ideológica do gabinete de governo sobre a probabilidade de os parlamentares dos partidos da coalizão apresentarem um RIC

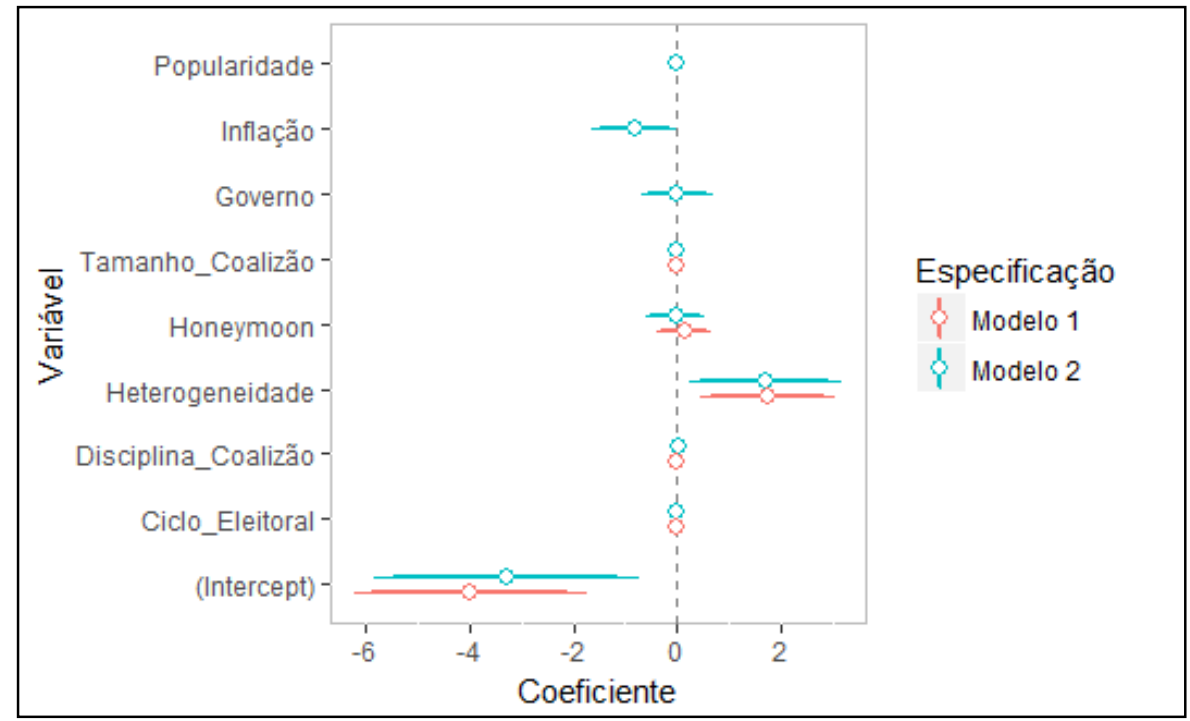

Fonte: Elaborado pelo autor.

Embora a variável inflação apresente significância estatística no modelo (de forma contrária às expectativas), assim como na primeira especificação (modelo 1), nenhum controle apresentou significância estatística e/ou substantiva. Com exceção do indicador heterogeneidade, todos os outros intervalos de confiança dos coeficientes estimados passam por zero, indicando efeito nulo dessas variáveis sobre a probabilidade de os parlamentares apresentarem RIC. Isso indica que o principal preditor do uso dos RIC pelos deputados dos partidos da coalizão de governo é o aumento da expectativa de perda de informação, representado no modelo do Gráfico 2 pelo indicador heterogeneidade. Ceteris paribus, a maior distância entre as preferências dos partidos que integram o gabinete de governo está relacionada com o aumento dos incentivos para que os partidos da coalizão realizem controle das ações de implementação dos seus parceiros de governo.

\section{Redes de controle intragabinete no presidencialismo brasileiro}

Composição e densidade das redes

$\mathrm{Na}$ seção anterior, mostrei que a delegação em governos com múltiplas preferências desencadeia conflitos intragabinete que se expressam no parlamento sob a forma de controle horizontal. Nesta, apresento as redes de controle formadas a partir do monitoramento mútuo entre os partidos que integram o gabinete de governo. Mais especificamente, a partir da coleta de informações diádicas e da composição de 
sociomatrizes, foi possível mapear as redes de controle horizontal na fase de implementação das políticas públicas do Executivo.

Dado um número $M$ de atores que integram a rede de controle horizontal em cada gabinete formado entre 1995 e 2014, uma sociomatriz é composta pela interseção de $\mathrm{N}$ relacionamentos entre os partidos do gabinete $-M \times M-$, em que cada célula representa o relacionamento entre dois atores (partidos) e a força dessa relação. Esta última é determinada pelo número de vezes que cada partido realiza ações de controle em relação a outro ator da rede.

Por exemplo, numa matriz (uma rede) hipotética $C M$, a força da relação entre o partido $\mathrm{G}$ e o partido $\mathrm{K}$ será dada pelo número de ações de controle que cada partido executa sobre o outro. Se nessa mesma matriz hipotética $\mathrm{G}$ é controlado 50 vezes e $\mathrm{K}$ é controlado 10 vezes, G estará necessariamente numa posição de maior centralidade na rede. A posição na rede é definida, dessa forma, pela intensidade de controle que cada ator executa e recebe. Atores mais centrais são aqueles que, em um dado gabinete, foram mais controlados pelos outros partidos presentes no governo.

A Tabela 4 apresenta as descritivas básicas das redes formadas nos 15 gabinetes analisados, nos governos FHC, Lula e Dilma. O número de atores da rede informa quantos partidos participaram das ações de controle horizontal. Esse número será sempre maior que o número de partidos da coalizão de governo em função dos partidos que não ocupam o gabinete, mas também realizam ações de controle. O número de relações da rede é o número de conexões estabelecidas pelos atores da rede. Esse número será sempre maior ou igual ao número de atores da rede. Isso porque cada ator pode controlar as ações de mais de um partido na mesma rede.

As redes formadas nos gabinetes foram classificadas em função da sua densidade, a qual é definida pela razão entre as relações existentes em toda a rede e as relações possíveis de existir $\left(k^{2}\right)^{30}$. Assim, quanto mais densa for a rede, mais coesa será a cadeia de vínculos entre esses atores (Wasserman e Faust, 1994). O indicador Densidade (Z) presente na Tabela 4 corresponde às densidades padronizadas ${ }^{31}$ das redes analisadas.

Por meio da padronização foi possível estabelecer um critério claro para a classificação das redes: aquelas com valores acima de um desvio-padrão positivo foram consideradas de alta densidade; aquelas com valores acima de um desvio-padrão negativo foram consideradas de baixa densidade; e as redes com números entre 0 e 1 (positivo ou negativo) foram consideradas de média densidade. O que qualifica o grupo das redes de baixa densidade é o pequeno número de atores e a baixa frequência de relações entre os atores. Em tais contextos, ainda que presente, a expectativa de perda de informação dos partidos que integram o governo é menor.

30 O cálculo das relações possíveis $(R)$ é realizado a partir da multiplicação do número total de atores da rede $(\mathrm{N})$ pelo número total de atores menos 1 [N-1]. Enquanto fórmula, $\mathrm{R}=\mathrm{N} \times \mathrm{N}-1$. Essa subtração faz-se necessária pela impossibilidade de algum ator relacionar-se consigo mesmo.

${ }^{31}$ A padronização em $Z$ scores indica quantos desvios-padrão um dado valor $X$ de densidade se afasta da média padronizada de todas as redes analisadas. 
MECANISMOS DE ALINHAMENTO DE PREFERÊNCIAS EM GOVERNOS MULTIPARTIDÁRIOS

Tabela 4

Descritivas das redes de controle horizontal (RIC) ${ }^{32}$

\begin{tabular}{|c|c|c|c|c|c|c|c|c|c|c|c|}
\hline Gabinete & $\begin{array}{c}\mathbf{N} . \\
\text { atores }\end{array}$ & $\begin{array}{c}\mathbf{N} . \\
\text { relações }\end{array}$ & $\begin{array}{c}\mathbf{N} . \\
\text { ações de } \\
\text { controle }\end{array}$ & $\begin{array}{c}\mathbf{N} . \\
\text { coalizão } \\
\text { [A] }\end{array}$ & $\begin{array}{c}\text { Partidos } \\
\text { coalizão } \\
\text { [B] }\end{array}$ & $\begin{array}{c}\text { N. } \\
\text { oposição } \\
\text { [C] }\end{array}$ & $\begin{array}{c}\text { Partidos } \\
\text { oposição } \\
\text { [D] }\end{array}$ & CEC & CEO & Densidade & $\begin{array}{c}\text { Densidade } \\
\text { (Z) }\end{array}$ \\
\hline FHC I 1 & 10 & 15 & 20 & 3 & 3 & 17 & 7 & 0,1 & 0,24 & 16,67 & $-0,30$ \\
\hline FHC I 2 & 9 & 15 & 63 & 33 & 4 & 30 & 5 & 0,83 & 0,6 & 16,88 & $-0,28$ \\
\hline FHC II 1 & 10 & 17 & 47 & 25 & 4 & 22 & 6 & 0,63 & 0,37 & 18,89 & $-0,01$ \\
\hline FHC II 2 & 6 & 6 & 9 & 4 & 2 & 5 & 4 & 0,2 & 0,13 & 7,2 & $-1,56$ \\
\hline Lula I 1 & 14 & 19 & 65 & 24 & 7 & 41 & 7 & 0,34 & 0,59 & 20,46 & 0,2 \\
\hline Lula I 2 & 14 & 18 & 64 & 38 & 8 & 26 & 6 & 0,48 & 0,43 & 19,38 & 0,06 \\
\hline Lula I 3 & 8 & 8 & 13 & 7 & 4 & 6 & 4 & 0,18 & 0,15 & 9,14 & $-1,3$ \\
\hline Lula I 4 & 7 & 7 & 6 & 3 & 5 & 3 & 3 & 0,06 & 0,1 & 8,17 & $-1,43$ \\
\hline Lula I 5 & 10 & 24 & 68 & 37 & 7 & 31 & 3 & 0,53 & 1,03 & 26,67 & 1,02 \\
\hline Lula II 1 & 8 & 9 & 26 & 19 & 8 & 7 & 3 & 0,24 & 0,23 & 10,29 & $-1,15$ \\
\hline Lula II 2 & 15 & 27 & 72 & 17 & 8 & 55 & 7 & 0,21 & 0,79 & 28,93 & 1,33 \\
\hline Lula II 3 & 14 & 25 & 116 & 60 & 7 & 56 & 7 & 0,86 & 0,8 & 26,92 & 1,06 \\
\hline Dilma I2 & 14 & 20 & 84 & 43 & 7 & 41 & 7 & 0,61 & 0,59 & 21,54 & 0,34 \\
\hline Dilma I2 & 16 & 23 & 73 & 26 & 7 & 47 & 14 & 0,37 & 0,34 & 24,53 & 0,74 \\
\hline Dilma I3 & 17 & 27 & 91 & 33 & 6 & 58 & 11 & 0,55 & 0,53 & 28,69 & 1,29 \\
\hline
\end{tabular}

Fonte: Elaborada pelo autor a partir dos dados da Câmara dos Deputados.

O baixo grau de heterogeneidade do gabinete FHC II2, por exemplo, é explicado pela pequena quantidade de atores e relações observada nessa rede. No caso das três redes de baixa densidade formadas durante os mandatos do presidente Lula (Lula I3, Lula I4 e Lula II1), é preciso considerar o pouco tempo de duração desses gabinetes. Ainda que nesses governos o nível de dispersão das preferências ideológicas seja alto, a média de 86 dias de duração dos gabinetes não configura tempo suficiente para que os conflitos intragabinete possam se expressar na arena parlamentar e suscitar controle por parte dos partidos da coalizão.

As redes de média densidade do período FHC (FHC I1, FHC I2, FHC II1) se distinguem das redes formadas nos governos Lula (Lula I1, Lula I2) e Dilma (Dilma I1 e Dilma I2) pela magnitude da densidade. No primeiro caso, as redes de média densidade sempre apresentam densidades padronizadas negativas, ao passo que nos outros dois casos as densidades padronizadas são sempre positivas. Isso indica, em primeiro lugar, que o número de atores e relações entre os partidos observados nas redes dos governos Lula e Dilma é sempre maior. Significa, também, que a prática de controle mútuo entre os parceiros de gabinete é mais comum quando comparado com os gabinetes formados no governo FHC. Nesses governos, o controle mútuo intragabinete ocorre de forma mais recorrente e com maior intensidade. Vale ressaltar, no entanto, que essas redes mais densas de controle observadas não são particulares aos governos petistas, mas uma decorrência dos custos envolvidos na constituição de complexas cadeias de delegação. Gabinetes com preferências ideológicas mais extremas aumentam a expectativa de

\footnotetext{
32 As redes foram construídas a partir de uma seleção aleatória estratificada - os estratos são os 15 gabinetes analisados -, levando em consideração os seguintes critérios: i) número de partidos que integram o gabinete; ii) duração do gabinete; e iii) peso de cada partido no gabinete em função do tempo de duração do gabinete. No total, foram amostradas 817 ações de controle do universo de 22.688 Requerimentos de Informação apresentados na Câmara dos Deputados entre 1995 e 2014.
} 
assimetria de informação dos partidos integrantes do gabinete e fomentam o mútuo controle durante o processo de implementação de políticas públicas.

As colunas $\mathrm{CEC}^{33}$ e $\mathrm{CEO}^{34}$ informam o controle efetivo dos partidos da coalizão (CEC) e o controle efetivo dos partidos da oposição (CEO). Tanto o CEC como o CEO têm a finalidade de ponderar a quantidade de ações de controle da coalizão e da oposição pelo número de partidos que integram a rede. Se numa rede qualquer os partidos da coalizão realizam 15 ações de controle através de 3 partidos, e os partidos da oposição realizam as mesmas 15 ações de controle através de 10 partidos, o controle executado pela coalizão é considerado mais efetivo, uma vez que os partidos desta foram capazes de realizar, no mesmo tempo, a mesma frequência de controle com um número menor de atores na rede. Desse modo, os dois indicadores devem ser analisados de forma conjunta: vis-à-vis os valores do CEO, maiores valores do CEC indicam maior controle efetivo dos partidos da coalizão.

Como informa a Tabela 4, o peso da coalizão nas redes de controle horizontal foi maior ou igual ao da oposição em 73,3\% (11) dos gabinetes formados. Tendo como referência a medida alternativa de tempo, o controle exercido pela coalizão foi mais efetivo em 5.817 (76\%) dos 7.655 dias de duração do gabinete, entre 1995 e 2014. Embora os partidos da oposição também desempenhem um papel no controle das ações ministeriais, a maior densidade das redes é explicada pelo controle executado pelos partidos da coalizão.

\section{Centralidade nas redes}

Na subseção anterior discuti as principais características das redes de controle horizontal constituídas nos 15 gabinetes multipartidários formados nos governos FHC, Lula e Dilma. Nesta seção respondo a uma importante pergunta: o que torna um partido do gabinete potencial alvo de controle dos seus parceiros? Se o mecanismo que explica a formação das redes de controle intragabinete é a motivação dos partidos da coalizão para agregar suas preferências às políticas, espero que as ações de controle dos partidos representados no gabinete se concentrem nas áreas ministeriais mais salientes, aquelas com mais recursos monetários para a implementação de políticas públicas. Do ponto de vista formal:

H2: quanto maior a saliência (medida pela proporção de recursos do orçamento federal) do ministério ocupado por um dado partido da coalizão de governo, maior a centralidade desse ator na rede de controle intragabinete.

\footnotetext{
33 O valor de CEC é dado pelo número de ações de controle dos partidos da coalizão [A], ponderado pelo número de partidos da coalizão que realizaram ações de controle $[B]$. Em termos aritméticos: $(A / B) * 10$.

${ }^{34} \mathrm{O}$ valor de CEO é dado pelo número de ações de controle dos partidos da oposição [C], ponderado pelo número de partidos da oposição que realizaram ações de controle [D]. Em termos aritméticos: (C/D)*10.
} 
MECANISMOS DE ALINHAMENTO DE PREFERÊNCIAS EM GOVERNOS MULTIPARTIDÁRIOS

A Figura 1 apresenta um exemplo gráfico das redes de controle intragabinete analisadas neste artigo ${ }^{35}$, tomando como exemplo o controle mútuo realizado no gabinete Lula II2 por meio dos RIC. As redes construídas são one mode (apenas um tipo de node ${ }^{36}$, nesse caso, o partido) e bidirecionais (os atores da rede podem controlar e receber controle). Todas as redes são compostas por nodes, que representam partidos, e setas, que representam o sentido do controle.

Os nodes (círculos) em tons de rosa representam os partidos da coalizão de governo. O partido formador do gabinete (PT) foi destacado com um tom mais forte de rosa. Os nodes de cor cinza representam os partidos da oposição. O tamanho dos nodes diz respeito ao número de vezes (intensidade) que um dado ator da rede faz e/ou recebe controle. A direção das setas indica o sentido do controle. Por exemplo, na rede em questão, o PCdoB controla quatro outros partidos do gabinete de governo: PDT, PP, PMDB e PT. O mesmo PCdoB não é controlado por nenhum partido. Existe um caso em que a seta sai de um partido para ele mesmo (PT), algo tecnicamente denominado loop na análise de redes. Isso significa que, além de controlar ministérios de outros partidos, os parlamentares também controlam as ações de implementação de ministérios delegados para ministros do seu próprio partido. Essa é uma consequência da expectativa de perda de informação inerente à composição de governos multipartidários.

\section{Topografia das redes de controle horizontal intragabinete (rede Lula II2)}

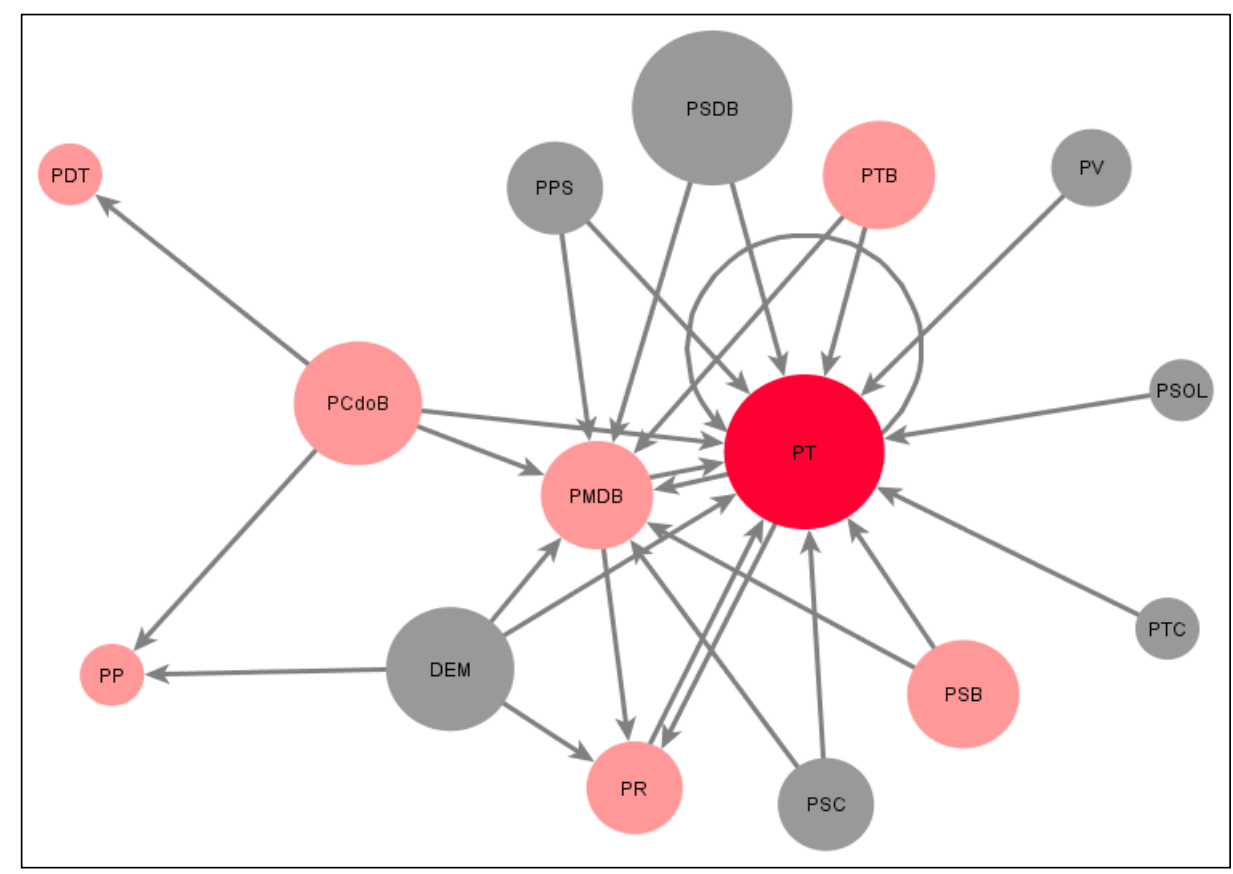

Fonte: Elaborada pelo autor a partir dos dados da Câmara dos Deputados.

\footnotetext{
35 Em virtude da limitação de espaço, os gráficos das outras redes não serão apresentados neste artigo.

36 Elemento gráfico que representa a unidade de análise fundamental de cada rede.
} 
A Tabela 8 (no Anexo) apresenta o ranking dos partidos em cada gabinete, de acordo com o grau de centralidade ${ }^{37}$ dos partidos nas redes de controle horizontal. 0 ranking dos partidos está disposto em ordem decrescente, do partido que recebeu menos controle (1) para o partido que recebeu mais controle dos seus parceiros de gabinete (4). Além do ordenamento dos partidos de acordo com o seu nível de centralidade na rede, a Tabela 8 traz informações sobre a porcentagem de recursos ${ }^{38}$ aprovados na Lei Orçamentária Anual (LOA) para o ministério que cada partido ocupava no momento da formação do gabinete e a porcentagem de controle recebido por cada um dos partidos ranqueados.

Dos 15 gabinetes formados no Brasil entre 1995 e 2014, em apenas três deles (FHC I1, FHC I2 e Lula I4) o partido formador e o seu principal parceiro ${ }^{39}$ não receberam a maior porcentagem de controle horizontal. Isto é, em $86 \%$ dos gabinetes, as redes de controle mútuo se constituem a partir do objetivo de monitorar os partidos que possuem mais recursos para implementar políticas. Como podemos observar na Figura 1, PT e PMDB, os partidos que, no gabinete Lula II2, ocupavam os ministérios que detinham a maior parcela do orçamento federal para a implementação de políticas públicas, são os atores mais centrais na rede. Por outro lado, o PCdoB, um partido que controlava parcela reduzida da LOA, é o ator que monitora a maior quantidade de partidos do governo.

Dito de forma mais clara, a intensidade do monitoramento recebido pelos partidos é dada por uma relação diretamente proporcional ao volume de recursos delegados a esses atores. Com o objetivo de avaliar o impacto do volume de recursos que cada partido do gabinete possui para implementar políticas públicas sobre o seu grau de centralidade nas redes intragabinete, foi realizado um teste bivariado entre o grau de centralidade dos atores na rede e o volume de recursos do orçamento (LOA) recebido por cada um. É preciso ressaltar que se trata apenas de testar de maneira mais sistemática a correlação entre as duas dimensões de análise.

$\mathrm{Na}$ Tabela 5, são reportados os resultados do modelo de mínimos quadrados ordinários (MQO). Nesse exercício empírico, a unidade de análise é o partido da coalizão

\footnotetext{
37 A operacionalização do cálculo para definir o grau de centralidade de cada ator nas redes de controle pode ser visualizada no Anexo.

${ }^{38}$ Esses recursos correspondem à soma dos recursos do Executivo que um partido controla. Se forem delegados para um partido W os ministérios da Educação e do Meio Ambiente, e essas pastas corresponderem a, respectivamente, $17 \%$ e $4 \%$ dos recursos do governo aprovados na LOA, considero que esse partido $\mathrm{W}$ possui $21 \%$ de recursos para policy.

39 No caso dos gabinetes formados durante os dois mandatos do presidente FHC, em dois (FHC I2 e FHC II2) dos quatro gabinetes formados o principal parceiro foi o PTB. Nos outros dois (FHC II1 e FHC II2), PFL e PMDB foram, respectivamente, os parceiros principais do PSDB, o partido formador do gabinete. Por ter seus recursos contingenciados com gastos previdenciários obrigatórios, o Ministério da Previdência Social delegado ao PFL nesse período - não foi considerado como uma área com recursos para policy. Por essa razão, em dois dos quatro gabinetes formados durante os dois mandados do presidente FHC, o PTB - e não o PFL - foi considerado o principal parceiro do partido formador do gabinete. Nos dois mandatos do presidente Lula e no primeiro mandato da presidente Dilma, houve apenas dois principais parceiros. Nos quatro primeiros gabinetes formados no período Lula (Lula I1, Lula I2, Lula I3 e Lula I4), o Partido Liberal (PL), partido do então vice-presidente da República José Alencar, assumiu o posto de principal parceiro do governo. Depois disso, em todos os gabinetes formados no período Lula e Dilma, o papel de principal parceiro foi ocupado pelo PMDB.
} 
MECANISMOS DE ALINHAMENTO DE PREFERÊNCIAS EM GOVERNOS MULTIPARTIDÁRIOS

que foi monitorado nas redes de controle horizontal ${ }^{40}$. A cada acréscimo de um ponto percentual na parcela de recursos do orçamento que cada partido detém, observa-se um aumento de 0.50 (completo), em média, numa escala de centralidade que varia entre 0 e 1. O efeito observado é maior no governo Lula (0.65) e menor no governo FHC (0.33). Embora esses resultados não devam ser interpretados de forma causal ${ }^{41}$, os altos valores do $\mathrm{R}^{2}$ indicam a grande capacidade explicativa da variável utilizada como preditora do grau de centralidade nas redes.

Em síntese, o que explica o grau de centralidade dos partidos nas redes de controle intragabinete é a quantidade de recursos para executar políticas que os partidos dispõem. Isso explica por que o partido formador e o seu principal parceiro de governo receberam, em média, $82 \%$ do monitoramento observado em todas as redes de controle analisadas.

Tabela 5

Grau de centralidade nas redes de controle horizontal em função do volume de recursos do orçamento (LOA)

\begin{tabular}{|l|c|c|c|c|}
\hline \multicolumn{1}{|c|}{ Variáveis } & $\begin{array}{c}\text { (I) } \\
\text { Completo }\end{array}$ & $\begin{array}{c}\text { (II) } \\
\text { FHC }\end{array}$ & $\begin{array}{c}\text { (III) } \\
\text { Lula }\end{array}$ & $\begin{array}{c}\text { (IV) } \\
\text { Dilma }\end{array}$ \\
\hline \multirow{2}{*}{$\%$ de recursos (LOA) } & $0.497^{* * *}$ & $0.334^{* * *}$ & $0.655^{* * *}$ & $0.563^{* * *}$ \\
\cline { 2 - 5 } & $(0.0455)$ & $(0.0619)$ & $(0.0743)$ & $(0.0418)$ \\
\hline \multirow{2}{*}{ Constante } & $0.401^{*}$ & 0.910 & 0.241 & $-0.0495^{*}$ \\
\cline { 2 - 5 } & $(0.208)$ & $(0.635)$ & $(0.150)$ & $(0.246)$ \\
\hline $\mathrm{N}$ & 159 & 35 & 58 & 66 \\
\hline $\mathrm{R}^{2}$ & 0.69 & 0.55 & 0.76 & 0.95 \\
\hline
\end{tabular}

Fonte: Elaborada pelo autor, com base em dados da Câmara dos Deputados e do Cebrap. Erro-padrão robusto entre parênteses.

Significância: *** $\mathrm{p}<0.01, * * \mathrm{p}<0.05, * \mathrm{p}<0.1$.

\section{Conclusão}

No presidencialismo brasileiro, os partidos que integram o gabinete não são indiferentes à agenda de políticas do Executivo. A fim de minorar os efeitos da assimetria de informação inerente à delegação em governos multipartidários, os partidos realizam controle das políticas públicas implementadas por seus parceiros de gabinete.

O fato de, nos sistemas presidencialistas, não haver interdependência entre os poderes Executivo e Legislativo não exclui a possibilidade de que os partidos integrantes das coalizões de governo sejam orientados por políticas. Embora as lógicas programática e clientelística não sejam mutuamente excludentes, o simples fato de empreenderem esforços para influenciar áreas de política delegadas para outros atores mostra que a motivação dos partidos não deve ser, a priori, julgada exclusivamente office-seeking ${ }^{42}$.

\footnotetext{
40 Nessa análise são considerados apenas os partidos que receberam controle pelo menos uma vez, exclusive os partidos que apenas realizaram controle sobre algum ator das redes constituídas.

41 Além da presença de outros controles, seria necessária a existência de alguma fonte de variação exógena (um instrumento, nesse caso) para que fosse possível interpretar a relação entre $\mathrm{X}$ e $\mathrm{Y}$ de maneira causal.

42 Conceito que define o modelo de atuação partidária no qual os partidos desejam, prioritariamente, maximizar seu controle sobre cargos na estrutura estatal. Assumindo que vencer eleições é o maior dos
} 
Ainda que os partidos possam pretender participar do governo com a finalidade de aumentar as chances de sucesso eleitoral (Downs, 1957; Riker, 1962), o uso de cargos e recursos monetários se converte em capital político apenas por meio da formulação e da execução de políticas públicas (Müller e Strom, 1999).

Isso não significa assumir que todos os partidos que ocupam o governo possuem uma agenda de políticas bem definida nem que o conteúdo destas seja sempre programático, mas que a expectativa de convergência é firmada em um pacto político de transferências de recursos para a implementação de políticas (Luebbert, 1986). Para além do oferecimento de cargos e uma parcela do orçamento federal, o acordo envolve o compartilhamento da agenda do Executivo (Limongi e Figueiredo, 2009), a cooperação e acordos mínimos em torno de programas e, no limite, a capacidade difusa de influenciar políticas públicas.

Todavia, algumas ponderações são devidas. Em primeiro lugar, o controle do processo de implementação exercido pelos partidos no Legislativo não é uma garantia de influência sobre as políticas. Ainda assim, permite que os partidos constranjam seus parceiros de governo, o que torna o controle horizontal um poderoso mecanismo de redução da assimetria de informação e de realinhamento de preferências. Em segundo lugar, o fato de poder influenciar o processo de implementação não implica controle dos resultados das políticas. Entre a proposição e a implementação existe um grande número de atores com capacidade para alterar o resultado de uma política pública (Arretche, 2001; Pressman e Wildavsky, 1984).

Não obstante essas observações, as redes de controle horizontal, de fato, variam em função do grau de dispersão de preferências do gabinete de governo. A alta correlação entre as duas dimensões é explicada pelo objetivo dos partidos de influenciar as políticas implementadas pelos seus parceiros de governo. Embora haja dessemelhanças no que diz respeito às condições de estruturação do governo (Elgie, 1997), diferentes dimensões microinstitucionais assentam-se nos mesmos moldes nas democracias parlamentaristas e presidencialistas (Cheibub, 2007). O argumento de que, por meio da combinação de aspectos institucionais, é possível produzir características semelhantes entre diferentes regimes de governo (Tsebelis, 1995) explica, por exemplo, por que são muito similares nos dois sistemas de governo os incentivos para que as coalizões de governo sejam formadas (Cheibub, Przeworski e Saiegh, 2004), a taxa de sucesso do Executivo (Figueiredo e Limongi, 2000) ou, ainda, as prerrogativas do Executivo e do Legislativo (Cheibub, Elkins e Ginsburg, 2014).

O arranjo institucional brasileiro não é, como sugeriu seminalmente Sérgio Abranches (1988), um caso discrepante nas democracias contemporâneas. O termo "presidencialismo de coalizão", cunhado pelo referido autor e equivocadamente elevado à condição de categoria analítica, contribuiu para diagnósticos imprecisos do funcionamento das instituições políticas brasileiras. Da mesma forma que nos contextos parlamentaristas,

objetivos partidários, ocupar o Executivo é a melhor das estratégias para acessar benefícios que Ihes garantam a permanência no poder (Riker, 1962). 
MECANISMOS DE ALINHAMENTO DE PREFERÊNCIAS EM GOVERNOS MULTIPARTIDÁRIOS

em presidencialismos multipartidários, os partidos que integram o governo podem competir por influência na agenda de políticas do Executivo.

Victor Araújo - Departamento de Ciência Política, Universidade de São Paulo. E-mail: <victor.asaraujo@usp.br>.

\section{Referências bibliográficas}

ABRANCHES, S. "Presidencialismo de coalizão: o dilema institucional brasileiro". Dados, vol. 31 , no 1 , p. 5-38, 1988 .

AlemÁN, E.; SAIEgh, S. M. "Legislative preferences, political parties, and coalition unity in Chile". Comparative Politics, vol. 39, no 3, p. 253-272, 2007.

AlemÁn, E.; TSEBelis, G. "Political parties and government coalitions in the Americas". Journal of Politics in Latin America, vol. 3, no 1, p. 3-28, 2011.

AMES, B. Os entraves da democracia no Brasil. Rio de Janeiro: FGV, 2003.

AMORIm Neto, O. "Gabinetes presidenciais, ciclos eleitorais e disciplina legislativa no Brasil". Dados, vol. 43, no 3, p. 479-519, 2000.

ANDEWEG, R. "Ministers as double agents? The delegation process between cabinet and ministers". European Journal of Political Research, vol. 37, no 3, p. 377-395, 2000.

ARAújo, V.; FreitAS, A.; VieirA, M. "The presidential logic of government formation in Latin American democracies". Revista de Ciencia Política, Chile. No prelo.

ARAújo, V.; SILVA, T.; VIEIRA, M. "Measuring presidential dominance over cabinets in presidential systems: constitutional design and power sharing". Brazilian Political Science Review, vol. 10, no 2, p. $1-23,2016$.

ARRETCHE, M. Uma contribuição para fazermos avaliações menos ingênuas. In: BARREIRA, M. C. R. N.; CARVALHO, M. C. B. (orgs.). Tendências e perspectivas na avaliação de políticas e programas sociais. São Paulo: IEE/PUC-SP, p. 43-56, 2001.

ATHEY, S.; Imbens, G. "The state of applied econometrics-causality and policy evaluation". Journal of Economic Perspectives, vol. 31, no 2, p. 3-32, 2017.

BATISTA, M. "O poder no Executivo: uma análise do papel da presidência e dos ministérios no presidencialismo de coalizão brasileiro (1995-2010)". Opinião Pública, vol. 19, no 2, p. 449-473, 2013.

. "Taking portfolios difference seriously: a composite measure based on policy, office, and budget in Brazil". Brazilian Political Science Review, vol. 11, no 1, p. 1-28, 2017.

BLEI, D. M.; NG, A. Y.; Jordan, M. I. "Latent dirichlet allocation". Journal of Machine Learning Research, vol. 3, no 1, p. 993-1.022, 2003.

BRASIL. Congresso. Câmara dos Deputados. Questão de Ordem 469/2004. Câmara dos Deputados: Centro de Documentação e Informação, 2004.

Congresso. Câmara dos Deputados. Regimento interno da Câmara dos Deputados (vol. 104). Edições Câmara, 2015. 
CARROLL, R.; COX, G. "Shadowing ministers monitoring partners in coalition governments". Comparative Political Studies, vol. 45, no 2, p. 220-236, 2012.

CHANG, J. LDA: Collapsed Gibbs sampling methods for topic models. R package version 1.3.2, 2012.

ChANG, J., et al. "Reading tea leaves: how humans interpret topic models". Advances in Neural Information Processing Systems, vol. 31, no 1, p. 288-296, 2009.

CheibuB, J. Presidentialism, parliamentarism, and democracy. New York. Cambridge University Press, 2007.

Cheibub, J.; Elkins, Z.; Ginsburg, T. "Beyond presidentialism and parliamentarism". British Journal of Political Science, vol. 44, no 3, p. 515-544, 2014.

Cheibub, J.; Przeworski, A.; SAIEgh, S. "Government coalition under parliamentarism and presidentialism". British Journal of Political Science, vol. 34, no 3, p. 565-587, 2004.

Downs, A. "An economic theory of political action in a democracy". The Journal of Political Economy, vol. 65, no 2, p. 135-150, 1957.

ELGIE, R. "Models of executive politics: a framework for the study of Executive Power relations in parliamentary and semi-presidential regimes". Political Studies, vol. 45, no 2, p. 217-231, 1997.

EPSTEIN, D.; O'HALLORAN, S. Delegating powers: a transaction costs politics approach to policy making under separate powers. New York: Cambridge University Press, 1999.

Figueiredo, A.; Limongi, F. Executivo e Legislativo na nova ordem constitucional. Rio de Janeiro: FGV, 1999.

. "Presidential power, legislative organization, and party behavior in Brazil". Comparative Politics, vol. 32, no 2, p. 151-170, 2000.

FreitAs, A. "O presidencialismo da coalizão". Tese de Doutorado. Departamento de Ciência Política, Universidade de São Paulo, São Paulo, 2013.

. "Unboxing the active role of the Legislative Power in Brazil". Brazilian Political Science. Review, vol. 10, no 2, p. 1-34, 2016.

GAYLORD, S.; RENNó, L. "Opening the black box: cabinet authorship of legislative proposals in a multiparty presidential system". Presidential Studies Quarterly, vol. 45, no 2, p. 247-269, 2015.

HORNIK, K.; GRUN, B. "Topicmodels: an R package for fitting topic models". Journal of Statistical Software, vol. 40, no 13, p. 1-30, 2011.

INÁCIO, M.; REZENDE, D. "Partidos legislativos e governo de coalizão: controle horizontal das políticas públicas". Opinião Pública, vol. 21, no 2, p. 296-335, 2015.

JAMES, G., et al. An introduction to statistical learning: with applications in R. London: Springer, 2013.

KInzo, M. D. "Partidos, eleições e democracia no Brasil pós-1985". Revista Brasileira de Ciências Sociais, vol. 19, no 54, p. 23-40, 2004.

LAVER, M. "Governmental politics and the dynamics of multiparty competition". Political Research Quarterly, vol. 61, no 3, p. 532-536, 2008.

LAVER, M.; SCHOFIELD, N. Multiparty government: the politics of coalition in Europe. University of Michigan Press, 1998. 
MECANISMOS DE ALINHAMENTO DE PREFERÊNCIAS EM GOVERNOS MULTIPARTIDÁRIOS

LAVER, M.; SHEPSLE, K. Cabinet ministers and parliamentary government. Cambridge: Cambridge University Press, 1994.

LEMOS, L. "Controle legislativo em democracias presidencialistas: Brasil e EUA em perspectiva comparada". Tese de doutorado, UnB, Brasília, 2005.

LEMOS, L.; POWER, T. "Determinantes do controle horizontal em parlamentos reativos: o caso do Brasil (1988-2005)". Dados, vol. 56, no 2, p. 383-412, 2013.

Limongi, F.; Figueiredo, A. Poder de agenda e políticas substantivas. In: InÁcio, M.; RenNó, L. (eds.). Legislativo brasileiro em perspectiva comparada. Belo Horizonte: Editora UFMG, 2009.

LUEBBERT, G. Comparative democracy: policymaking and governing coalitions in Europe and Israel. New York: Columbia University Press, 1986.

MAGAR, E.; MORAES, J. "Factions with clout: presidential cabinet coalition and policy in the Uruguayan parliament". Party Politics, vol. 18, no 3, p. 427-451, 2012.

Martin, L. W.; VAnberg, G. Parliaments and coalitions: the role of legislative institutions in multiparty governance. Oxford: Oxford University Press, 2011.

MARTIN, S. "Policy, office and votes: the electoral value of ministerial office". British Journal of Political Science, vol. 46, no 2, p. 281-296, 2016.

Melo, C. R.; NunES, F. Ideologia e distância entre preferências: uma comparação dos governos Lagos e Lula. In: InÁcio, M.; RenNó, L. (eds.). Legislativo brasileiro em perspectiva comparada. Belo Horizonte: Editora UFMG, 2009.

Melo, M. A.; Pereira, C. Making Brazil work: checking the president in a multiparty system. London: Palgrave Macmillan, 2013.

MOURY, C. Coalition government and party mandate: how coalition agreements constrain ministerial action. London: Routledge, 2013.

MüLler, W.; Strom, K. Policy, office, or votes?: how political parties in Western Europe make hard decisions. New York: Cambridge University Press, 1999.

. Coalition governments in Western Europe. Oxford: Oxford University Press, 2003.

O’DONNELL, G. A. "Horizontal accountability in new democracies". Journal of Democracy, vol. 9, no 3, p. $112-126,1998$.

Power, T.; Zucco, C. "Estimating ideology of Brazilian legislative parties, 1990-2005: a research communication". Latin American Research Review, vol. 44, no 1, p. 218-246, 2009.

PRESSMAN, J. L.; WildAVSKY, A. B. Implementation: how great expectations in Washington are dashed in Oakland. Los Angeles: University of California Press, 1984.

Raile, E.; Pereira, C.; Power, T. "The executive toolbox: building legislative support in a multiparty presidential regime". Political Research Quarterly, vol. 64, no 2, p. 323-334, 2011.

RenNó, L.; WoJCIK, S. "The changing role of ministers in the legislative agenda in Brazil". Revista Ibero-Americana de Estudos Legislativos, vol. 4, no 1, p. 57-69, 2015.

RIKER, W. The theory of political coalitions. New Haven: Yale University Press, 1962.

Russell, M.; Gover, D.; Wollter, K. "Does the Executive dominate the Westminster legislative process?: six reasons for doubt". Parliamentary Affairs, vol. 69, no 2, p. 286-308, 2016. 
STROM, K.; MüLlER, W. "Parliamentary control of coalition governments". Annual Review Political Science, vol. 13, p. 517-535, 2010.

THIES, M. F. "Keeping tabs on partners: the logic of delegation in coalition governments". American Journal of Political Science, vol. 45, n³, 580-598, 2001.

TSEBeLIS, G. "Decision making in political systems: veto players in presidentialism, parliamentarism, multicameralism and multipartyism". British Journal of Political Science, vol. 25, no 3, p. 289-325, 1995.

WASSERMAN, S.; FAUST, K. Social network analysis: methods and applications. Cambridge: Cambridge University Press, 1994.

Zucco, C. "Legislative coalitions in presidential systems: the case of Uruguay". Latin American Politics and Society, vol. 55, no 1, 2013.

\section{Anexo}

Cálculo do grau de heterogeneidade do gabinete

Grau de heterogeneidade do gabinete [varia entre 0 e 1] - quanto maior $o$ valor desse indicador, maior a distância entre as preferências dos atores presentes no gabinete.

$$
\sum_{n=1}^{n} \mid \frac{|x-x i|}{n}
$$

Onde, $x=$ preferência (score) do partido formador;

$x i=$ preferência do partido $(\mathrm{x})$ integrante do gabinete;

$n=$ número de partidos que integram o gabinete.

Cálculo do grau de centralidade do ator na rede

Medida padronizada do grau de centralidade dos atores partidários que integram as redes de controle intragabinete [varia entre 0 e 1 ]. Quanto maior $o$ valor desse indicador, maior o grau de centralidade de um dado ator na rede.

$$
C^{\prime} D\left(n_{i}\right)=\frac{X i+}{g-1} \quad C^{\prime} D\left(n_{i}\right)=\frac{\frac{\Sigma i j}{j}}{g-1}
$$

Onde,

$\mathrm{xi}=$ número relações observadas na rede;

$\mathrm{g}=$ número de relações possíveis. 
MECANISMOS DE ALINHAMENTO DE PREFERÊNCIAS EM GOVERNOS MULTIPARTIDÁRIOS

Tabela 6

Determinantes de controle horizontal intragabinete

\begin{tabular}{|c|c|c|c|c|}
\hline \multirow[t]{2}{*}{ Variáveis } & \multicolumn{2}{|r|}{ (I) } & \multicolumn{2}{|r|}{ (II) } \\
\hline & Coeficiente & Razão de chance & Coeficiente & Razão de chance \\
\hline \multicolumn{5}{|c|}{ Fatores endógenos } \\
\hline \multirow{2}{*}{ Heterogeneidade } & $1.7393 * * *$ & $5.6939 * * *$ & $1.6911 * * *$ & $5.4258 * * *$ \\
\hline & $(0.6607)$ & $(3.7622)$ & $(0.7478)$ & 4.0575 \\
\hline \multirow{2}{*}{$\begin{array}{c}\text { Tamanho } \\
\text { coalizão }\end{array}$} & $0.0049 * * *$ & $1.0049 * * *$ & 0.0031 & 1.0031 \\
\hline & $(0.0019)$ & $(0.0019)$ & $(0.0026)$ & $(0.0026)$ \\
\hline \multirow{2}{*}{$\begin{array}{l}\text { Disciplina } \\
\text { coalizão }\end{array}$} & 0.0051 & 1.0051 & 0.0077 & 1.0077 \\
\hline & $(0.0133)$ & $(0.0134)$ & $(0.0148)$ & $(0.0149)$ \\
\hline \multicolumn{5}{|c|}{ Fatores exógenos } \\
\hline \multirow{2}{*}{ Popularidade } & & & 0.0007 & 1.0007 \\
\hline & & & $(0.0070)$ & $(0.0070)$ \\
\hline \multirow{2}{*}{ Inflação } & & & $-0.8238 * *$ & $0.4387 * * *$ \\
\hline & & & $(0.4096)$ & $(0.1797)$ \\
\hline \multicolumn{5}{|l|}{ Controles } \\
\hline \multirow{2}{*}{ Ciclo eleitoral } & 0.0002 & 1.0002 & 0.0004 & 1.0004 \\
\hline & $(0.0002)$ & $(0.0002)$ & $(0.0003)$ & $(0.0003)$ \\
\hline \multirow{2}{*}{ Honeymoon } & 0.1336 & 1.1430 & -0.0276 & 0.9727 \\
\hline & $(0.2744)$ & $(0.3137)$ & $(0.2888)$ & 0.2809 \\
\hline \multirow{2}{*}{ Governo } & & & 0.0029 & 1.0029 \\
\hline & & & $(0.3485)$ & $(0.3485)$ \\
\hline \multirow{2}{*}{ Constante } & $-3.9702 * * *$ & $0.0188 * * *$ & $-3.2955 * * *$ & $0.0370 * * *$ \\
\hline & $(1.1442)$ & $(0.0215)$ & $(1.3021)$ & $(0.04824)$ \\
\hline Log likehood & -531.1935 & -531.1935 & -528.6820 & -528.6820 \\
\hline $\mathrm{N}$ & 817 & 817 & 817 & 817 \\
\hline
\end{tabular}

Fonte: Elaborada pelo autor. 
Tabela 7

Lista das dez áreas ministeriais mais controlados pelos partidos da coalizão de governo (FHC, Lula e Dilma)

\begin{tabular}{|c|c|c|c|c|c|c|}
\hline \multicolumn{3}{|c|}{ FHC } & \multicolumn{2}{|c|}{ Lula } & \multicolumn{2}{|c|}{ Dilma } \\
\hline Ranking & Ministério & Termos & Ministério & Termos & Ministério & Termos \\
\hline 1 & Planejamento & $\begin{array}{c}\text { orçament, } \\
\text { gesta, } \\
\text { planej, } \\
\text { emend, }\end{array}$ & $\begin{array}{c}\text { Meio } \\
\text { Ambiente }\end{array}$ & $\begin{array}{c}\text { ambient, } \\
\text { amazon, } \\
\text { regia, } \\
\text { seguranc }\end{array}$ & $\begin{array}{c}\text { Desenvolvimento } \\
\text { Social }\end{array}$ & $\begin{array}{c}\text { desenvolv, } \\
\text { social, } \\
\text { combat, } \\
\text { previden }\end{array}$ \\
\hline 2 & Minas e Energia & $\begin{array}{c}\text { energ, } \\
\text { petrol, eletr, } \\
\text { petrobras }\end{array}$ & Saúde & $\begin{array}{l}\text { saud, infantil, } \\
\text { doenc, } \\
\text { mortal }\end{array}$ & Transportes & $\begin{array}{l}\text { transport, } \\
\text { execuça, } \\
\text { obras, port }\end{array}$ \\
\hline 3 & Fazenda & $\begin{array}{l}\text { fazend, } \\
\text { econom, } \\
\text { arrecad, } \\
\text { impost }\end{array}$ & Transportes & $\begin{array}{l}\text { transport, } \\
\text { sistem, } \\
\text { obras, rodov }\end{array}$ & Planejamento & $\begin{array}{c}\text { planej, } \\
\text { gesta, } \\
\text { orçament, } \\
\text { pac }\end{array}$ \\
\hline 4 & Comunicações & $\begin{array}{c}\text { comunic, } \\
\text { privatiz, } \\
\text { cultur, radio }\end{array}$ & Planejamento & $\begin{array}{c}\text { gesta, } \\
\text { orçament, } \\
\text { planej, } \\
\text { emend }\end{array}$ & Comunicações & $\begin{array}{c}\text { tecnolog, } \\
\text { cienc, } \\
\text { comunic, } \\
\text { concessa }\end{array}$ \\
\hline 5 & $\begin{array}{l}\text { Previdência } \\
\text { Social }\end{array}$ & $\begin{array}{l}\text { social, } \\
\text { prevident, } \\
\text { assistenc, } \\
\text { inss }\end{array}$ & Justiça & $\begin{array}{c}\text { justic, políc, } \\
\text { providenc, } \\
\text { mort }\end{array}$ & Economia & $\begin{array}{l}\text { fazend, } \\
\text { receit, } \\
\text { estim, } \\
\text { financ }\end{array}$ \\
\hline 6 & Saúde & $\begin{array}{c}\text { saud, } \\
\text { hospital, } \\
\text { manutença, } \\
\text { sant }\end{array}$ & $\begin{array}{l}\text { Indústria e } \\
\text { Comércio }\end{array}$ & $\begin{array}{c}\text { desenvolv, } \\
\text { exterior, } \\
\text { industr, } \\
\text { comerci }\end{array}$ & Saúde & $\begin{array}{l}\text { saud, } \\
\text { atend, } \\
\text { recurs, } \\
\text { hospit }\end{array}$ \\
\hline 7 & $\begin{array}{l}\text { Indústria e } \\
\text { Comércio }\end{array}$ & $\begin{array}{c}\text { desenvolv, } \\
\text { exterior, } \\
\text { industr, } \\
\text { comerci }\end{array}$ & $\begin{array}{l}\text { Minas e } \\
\text { Energia }\end{array}$ & $\begin{array}{c}\text { energ, petrol, } \\
\text { eletr, } \\
\text { petrobras }\end{array}$ & Educação & $\begin{array}{c}\text { educ, } \\
\text { cultur, } \\
\text { escol, } \\
\text { haddad } \\
\end{array}$ \\
\hline 8 & Meio Ambiente & $\begin{array}{c}\text { ambient, } \\
\text { amazon, } \\
\text { hidric, ibam }\end{array}$ & Comunicações & $\begin{array}{l}\text { comunic, } \\
\text { implant, } \\
\text { ongs, radi }\end{array}$ & $\begin{array}{l}\text { Indústria e } \\
\text { Comércio }\end{array}$ & $\begin{array}{c}\text { desenvolv, } \\
\text { exterior, } \\
\text { industr, } \\
\text { comerci }\end{array}$ \\
\hline 9 & Agricultura & $\begin{array}{c}\text { agricultur, } \\
\text { comerci, } \\
\text { agrar, } \\
\text { import }\end{array}$ & Educação & $\begin{array}{l}\text { educ, repro, } \\
\text { integra, escol }\end{array}$ & Minas e Energia & $\begin{array}{c}\text { energ, } \\
\text { petrol, } \\
\text { eletr, } \\
\text { petrobras }\end{array}$ \\
\hline 10 & Transportes & $\begin{array}{l}\text { transport, } \\
\text { sistem, } \\
\text { obras, rodov }\end{array}$ & Agricultura & $\begin{array}{c}\text { agricultur, } \\
\text { comerci, } \\
\text { agrar, import }\end{array}$ & Agricultura & $\begin{array}{c}\text { desenvolv, } \\
\text { exterior, } \\
\text { industr, } \\
\text { comerci }\end{array}$ \\
\hline
\end{tabular}

Fonte: Elaborada pelo autor a partir das informações da Câmara dos Deputados. 
MECANISMOS DE ALINHAMENTO DE PREFERÊNCIAS EM GOVERNOS MULTIPARTIDÁRIOS

Tabela 8

Posição dos atores nas redes de controle intragabinete no presidencialismo brasileiro (FHC, Lula, Dilma) (\%)

\begin{tabular}{|c|c|c|c|c|c|c|c|c|c|c|c|c|}
\hline & \multicolumn{3}{|c|}{ FHC I1 } & \multicolumn{3}{|c|}{ FHC I2 } & \multicolumn{3}{|c|}{ FHC II1 } & \multicolumn{3}{|c|}{ FHC II2 } \\
\hline Ranking & Partido & Recursos & Controle & Partido & Recursos & Controle & Partido & Recursos & Controle & Partido & Recursos & Controle \\
\hline 1 & PFL & 3,35 & 52,38 & PSDB & 24,34 & 56,25 & PSDB & 38,11 & 63,27 & PSDB & 39,58 & 75 \\
\hline 2 & PSDB & 49,87 & 38,10 & PFL & 3,11 & 20,31 & PFL & 21,91 & 22,45 & PMDB & 11,16 & 12,5 \\
\hline 3 & PMDB & 11,14 & 9,52 & PMDB & 10,36 & 12,50 & PMDB & 11,61 & 10,20 & PPB & 3,69 & 12,5 \\
\hline \multirow[t]{2}{*}{4} & PTB & 20,5 & 4,76 & PTB & 21,77 & 4,69 & PPB & 15,21 & 2,04 & & & \\
\hline & \multicolumn{3}{|c|}{ Lula I1 } & \multicolumn{3}{|c|}{ Lula I2 } & \multicolumn{3}{|c|}{ Lula I3 } & \multicolumn{3}{|c|}{ Lula I4 } \\
\hline Ranking & Partido & Recursos & Controle & Partido & Recursos & Controle & Partido & Recursos & Controle & Partido & Recursos & Controle \\
\hline 1 & PT & 57,37 & 69,70 & PT & 64,02 & 82,81 & PT & 65,17 & 85,71 & PT & 65,17 & 73,33 \\
\hline 2 & $\mathrm{PL}$ & 7,79 & 9,09 & $\mathrm{PL}$ & 22,05 & 9,38 & $\mathrm{PL}$ & 20,99 & 7,14 & $\mathrm{PL}$ & 20,99 & 16,67 \\
\hline 3 & PDT & 1,42 & 4,55 & PTB & 1,25 & 6,25 & PMDB & 1,87 & 7,14 & PMDB & 1,87 & 10 \\
\hline \multirow[t]{2}{*}{4} & PV & 0,28 & 4,55 & PMDB & 0,27 & 1,56 & & & & & & \\
\hline & \multicolumn{3}{|c|}{ Lula I5 } & \multicolumn{3}{|c|}{ Lula II1 } & \multicolumn{3}{|c|}{ Lula II2 } & \multicolumn{3}{|c|}{ Lula II3 } \\
\hline Ranking & Partido & Recursos & Controle & Partido & Recursos & Controle & Partido & Recursos & Controle & Partido & Recursos & Controle \\
\hline 1 & PT & 42,64 & 65,22 & PT & 35,15 & 56,25 & PT & 43,58 & 61,64 & PT & 37,88 & 43,52 \\
\hline 2 & PMDB & 41,42 & 20,29 & PMDB & 43,58 & 12,5 & PMDB & 32,62 & 28,77 & PMDB & 40,19 & 43,52 \\
\hline 3 & PR & 4,64 & 7,25 & PR & 3,70 & 6,25 & PR & 3,70 & 5,48 & PR & 3,90 & 11,11 \\
\hline \multirow[t]{2}{*}{4} & PSB & 1,63 & 2,90 & PSB & 0,71 & 6,25 & PP & 1,10 & 2,74 & $\mathrm{PP}$ & 3,08 & 0,93 \\
\hline & \multicolumn{3}{|c|}{ Dilma I1 } & \multicolumn{3}{|c|}{ Dilma I2 } & \multicolumn{3}{|c|}{ Dilma I3 } & & & \\
\hline Ranking & Partido & Recursos & Controle & Partido & Recursos & Controle & Partido & Recursos & Controle & & & \\
\hline 1 & PT & 54,96 & 81,82 & PT & 57,68 & 66,67 & PT & 58,98 & 77,57 & & & \\
\hline 2 & PMDB & 18,77 & 6,49 & PMDB & 17,82 & 21,33 & PMDB & 19,29 & 14,95 & & & \\
\hline 3 & PP & 5,00 & 3,90 & PR & 4,66 & 6,67 & PDT & 8,88 & 4,67 & & & \\
\hline 4 & PSB & 1,25 & 1,30 & $\mathrm{PP}$ & 4,57 & 2,67 & PP & 4,87 & 0,93 & & & \\
\hline
\end{tabular}

Fonte: Elaborada pelo autor a partir das informações da Câmara dos Deputados.

\section{Resumo}

Mecanismos de alinhamento de preferências em governos multipartidários: controle de políticas públicas no presidencialismo brasileiro

A formação de governos multipartidários potencializa o risco de assimetria de informação entre principals e agentes, de maneira que os conflitos do gabinete sobre políticas se refletem no comportamento dos partidos no parlamento. Diversos estudos demonstram que o controle mútuo entre os partidos integrantes do gabinete é uma forma de compensar a perda de informação inerente à delegação. Enquanto a literatura costuma focar na fase de formulação das políticas, analisando os governos formados no Brasil entre 1995 e 2014, argumento que existe um conjunto mais diversificado de estratégias que permitem aos partidos escrutinar as políticas implementadas por seus parceiros de gabinete. Fazendo uso de análise de redes e técnicas quantitativas de análise de texto (método Gibbs Sampling, algoritmo bayesiano derivado do Latent Dirichlet allocation - LDA) mostro que, nas situações em que os portfólios ministeriais são distribuídos para atores com distintas preferências sobre políticas, os partidos intensificam o uso dos Requerimentos de Informação (RIC) para monitorar os ministérios e políticas que lhes interessam. A estrutura das redes de controle intragabinete varia em função da saliência dos ministérios: os partidos responsáveis pelos portfólios com maior dotação orçamentária são os atores com maior grau de centralidade nas redes de monitoramento mútuo.

Palavras-chave: presidencialismo; coalizões de governo; políticas públicas; análise de redes; machine learning 


\section{Abstract}

Preference alignment in multiparty governments: control of public policy in Brazilian presidentialism

The formation of multiparty governments increases the risk of asymmetry of information between principals and agents so that the cabinet's policy conflicts are reflected in the behavior of parties in parliament. Several studies reveal that mutual control between cabinet parties is a way to compensate for the loss of information inherent in the delegation. While analysts often focus on the policy-making process, I argue that there is a more diverse set of strategies that allow parties to scrutinize policies implemented by their cabinet partners. To test this argument, I analyze the multiparty governments formed in Brazil between 1995 and 2014. I use network analysis and machine learning-Gibbs Sampling Method, Bayesian algorithm derived from Latent Dirichlet allocation (LDA)-to show that, in situations in which ministerial portfolios are distributed to actors with different policy preferences, parties intensify the use of Information Requirements (RIC), an important tool for horizontal control, to monitor the ministries, policies, and programs that interest them. The structure of the intra-cabinet control networks varies according to the importance of the ministries: the parties allocated in the ministries with the largest portion of the federal budget-those with the most resources for the implementation of public policies-are the actors with the greatest degree of centrality in the intracabinet mutual control networks.

Keywords: presidentialism; government coalitions; public policy; network analysis; machine learning

\section{Resumen}

Mecanismos de alineamiento de preferencias en gobiernos multipartidistas: control de las políticas públicas en el presidencialismo brasileño

La formación de gobiernos multipartidistas potencializa el riesgo de asimetría de información entre principals y agentes, de manera que los conflictos del gabinete sobre políticas se reflejan en el comportamiento de los partidos en el parlamento. Diversos estudios demuestran que el control mutuo entre los partidos integrantes del gabinete es una forma de compensar la pérdida de información inherente a la delegación. Mientras los analistas suelen enfocarse en la fase de formulación de las políticas, analizando los gobiernos formados en Brasil, entre 1995 y 2014, argumento en este trabajo que existe un conjunto más diversificado de estrategias que permiten a los partidos escudriñar las políticas implementadas por sus socios de gabinete. Utilizo análisis de redes y técnicas cuantitativas de análisis de texto - Método Gibbs Sampling, algoritmo bayesiano derivado del Latent Dirichlet allocation (LDA) - para mostrar que, en las situaciones en que los portafolios ministeriales se distribuyen a actores con distintas preferencias sobre políticas, los partidos intensifican el uso de los Requerimientos de Información (RIC), un importante instrumento de control horizontal, para monitorear los ministerios, políticas y programas que les interesan. La estructura de las redes de control horizontal intragabinete varía en función de la importancia de los ministerios: los partidos responsables de las carteras con mayor dotación presupuestaria - aquellos con más recursos para la implementación de políticas públicas - son los actores con mayor grado de centralidad en las redes de control mutuo.

Palabras clave: presidencialismo; coaliciones de gobierno; políticas públicas; análisis de redes; machine learning

\section{Résumé}

Mécanismes d'alignement de préférences dans les gouvernements multipartites : le contrôle des politiques publiques dans le présidentialisme brésilien

La formation des gouvernements pluripartites intensifie le risque de l'asymétrie d'information entre des principals et des agents, de sorte que les conflits du cabinet sur les politiques se reflètent dans le comportement des partis au Parlement. Plusieurs études ont démontré que le contrôle mutuel entre les partis intégrant le cabinet est un moyen de compenser la perte d'information inhérente à la délégation. Alors que les analystes se concentrent souvent sur le moment de la formulation des politiques, avec l'analyse des gouvernements formés au Brésil entre 1995 et 2014, je soutiens dans ce travail qu'il existe un ensemble plus diversifié de stratégies qui permettent aux partis de surveiller les politiques mises en œuvre par les partenaires du cabinet. Grâce à l'analyse de réseau et les 
MECANISMOS DE ALINHAMENTO DE PREFERÊNCIAS EM GOVERNOS MULTIPARTIDÁRIOS

techniques quantitatives d'analyse de texte - Méthode Gibbs Sampling, algorithme bayésien dérivé du Latent Dirichlet allocation (LDA) - je montre que, dans les situations où les portefeuilles ministériels sont distribués à des acteurs ayant des préférences divergentes sur les politiques, les partis intensifient l'utilisation des Requêtes d'Information (RIC), un important instrument de contrôle horizontal pour surveiller les ministères, les politiques et les programmes qui les concernent. La structure des réseaux de contrôle horizontal dans le cabinet varie en fonction de I'importance des ministères: les partis responsables pour les dossiers avec les plus grandes allocations budgétaires ceux qui ont plus de ressources pour la mise en œuvre des politiques publiques - sont les acteurs ayant le degré de centralité le plus élevé dans les réseaux de contrôle mutuel, c'est-à-dire que ce sont ceux qui reçoivent la majeure partie du contrôle de leurs partenaires du gouvernement.

Mots-clés: présidentialisme; gouvernement de coalition; les politiques publiques; analyse de réseaux; machine learning

Artigo submetido à publicação em 11 de agosto de 2016.

Versão final aprovada em 3 de julho de 2017. 